TAO, Vol.7, No.1, 83-105, March 1996

\title{
An Exploratory Study of the Relationship Between Annual Frequency of Invaded Typhoons in Taiwan and EI Nino/Southern Oscillation
}

\author{
JEN-CHENG JOSEPH CHANG ${ }^{1}$
}

(Manuscript received 6 January 1995, in final form 30 January 1996)

\begin{abstract}
In this study, a nonlinear association between the characteristics of invaded typhoons (hereafter, referred to as ITYs) in Taiwan and sea surface temperature anomalies (SSTAs) over the equatorial eastern Pacific is identified. The relation is such that the years with a warmer-than-normal SSTA condition in the late season generally correspond to fewer annual ITYs $(<4)$, while those with a cooler SSTA are basically associated with more ITYs $(\geq 4)$. When the SSTA becomes too cold $\left(\leq-1.0^{\circ} \mathrm{C}\right)$, however, the annual total number of ITYs is, in fact, greatly reduced $(\sim 1-2)$ instead of being increased.

It is suggested that such a phenomenon is caused by different large-scale atmospheric responses to the underlying sea surface temperature conditions. A lower-level anti-cyclonic circulation with strong divergence suppresses the usual activities of tropical cyclones over the western North Pacific (WNP) in the cold years. An opposite mechanism occurs in the early season of the cool years. During the warm years, the typhoon activities over the WNP are not necessarily suppressed but are rather displaced eastward in response to an anomalous cyclonic circulation over the eastern part of WNP. Under such a configuration, however, Taiwan is not in the path of the preferential storm track.

This observation appears to be useful in the long term forecasting of typhoon activities in the Taiwan area, as long as the SSTAs can be predicted.
\end{abstract}

(Key Words: El Niño/Southern Oscillation, Invaded typhoons in Taiwan)

\section{INTRODUCTION}

The invasion of typhoons is one of the most important weather events in Taiwan for its direct link to one of the most important climatic (or weather) parameters, namely, rainfall. Summer rainfall from invaded typhoons (ITYs) is the major water resource for most parts of

1 Research and Development Center, Central Weather Bureau, 64, Kung-Yuan Road, Taipei, Taiwan R.O.C 
the island. Naturally, an excessive amount can result in floods, while the reverse can cause droughts, with the most recent examples being the years of 1994 (7 ITYs) and 1993 (1 ITYs), respectively. Either one of these extremely anomalous climate situations (i.e., much above or below the averaged number of ITYs) may cause a lot of damage to both the agricultural activities and the socioeconomic system of the island. In fact, the loss of property and human life due to typhoon invasions is the greatest among all disasters from weather, as reported by Shieh and Chen (1985). Accordingly, we would have a better stand from which to prepare ourselves for such disasters, were we able to understand the characteristics of these in advance.

From the viewpoint of short-term climate predictions, the actual number of ITYs there will be during the upcoming typhoon season is probably the most practical question that one would ask. Indeed, the interannual variability of yearly total ITYs in Taiwan is pronounced (Figure 1). According to the figure, while the average number of ITYs is about 3-4 per year, there can be as many as 8 or even none at all. It should be noted that although the typhoon season in Taiwan is generally from July to September, it can begin as early as April and last until late November. Thus, some other practical questions may be asked are: What is the onset month of the season? When does the season end? How many ITYs are there in the main season, which includes July, August and September (JAS), the early season, April, May and June (AMJ), or the late season, October and November (ON), respectively? As a starting point, only the first question is addressed here. It should also be noted that the typhoon tracking problem as well as the understanding of the preferentially large-scale dynamical condition for typhoon formation over the western North Pacific (WNP) are tackled by confining the scope of this study to local interest (see Section 3.1.2)), since the Taiwan area only occupies a small part of the WNP basin.
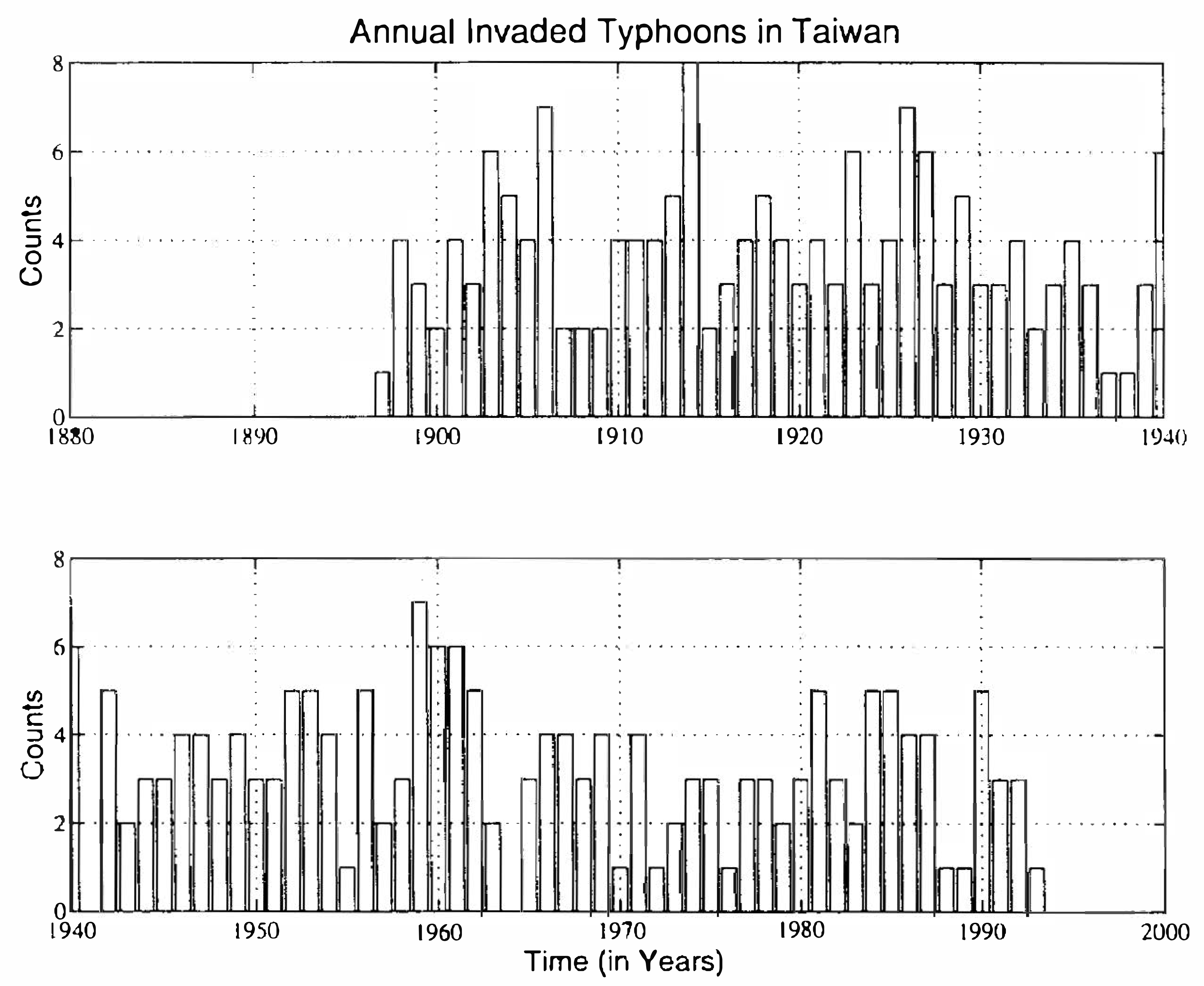

Fig. 1. Time series of the annual total number of ITYs in the Taiwan area (i.e., $\langle\mathrm{TY}\rangle_{\mathrm{tw}}$ ) in the period of $1897-1993$. 
The development and maintenance of typhoons (or more generally, tropical cyclones) primarily depends on the heat supply from the ocean (e.g., Emanuel 1986). It is also known that the heat flux is closely related to the sea surface temperature (SST), in addition to the atmospheric conditions. On acknowledging that the El Niño/Southern Oscillation (ENSO) event is by far the most noticeable, interannual, large-scale, air-sea interaction system, it is tempting to assume that the yearly characteristics of typhoons may be related to variations in tropical SSTAs over the eastern and central Pacific. The formation region of tropical cyclones over the WNP has been verified as being generally associated with ENSO in that the region spreads into the tropical central Pacific in El Niño years, while it mostly confines itself to the west of $160^{\circ} \mathrm{E}$ in La Niña years (e.g., Lander 1994; Wu and Lau 1992). Thus, the possible relationship between the annual frequency of ITYs in Taiwan and the SSTAs of the equatorial eastern Pacific is explored first.

Researches on relating local climate statistics in Taiwan to ENSO had not been emphasized until recently. Following the findings of Ropelewski and Halpert $(1987,1989)$ and Halpert and Ropelewski (1992) in global scale (in space) and in seasonal scale (in time), Hsu and Chen (1994) also investigated the empirical relationship between short-term climate variability (primarily on the surface temperature and precipitation) in the Taiwan area and the variation of tropical SSTAs in monthly scales. Their results show that the temperature in September, and the precipitation in March tend to be above (below) normal following the El $\mathrm{Niño} \mathrm{(La} \mathrm{Niña)} \mathrm{winters.} \mathrm{Except} \mathrm{for} \mathrm{that,} \mathrm{studies} \mathrm{at} \mathrm{the} \mathrm{Central} \mathrm{Weather} \mathrm{Bureau} \mathrm{(CWB)} \mathrm{of}$ Taiwan generally suggested that the local climate variations are more connected to the SSTAs over the North Pacific area centered at $\left(20^{\circ} \mathrm{N}, 150^{\circ} \mathrm{E}\right)$, rather than to the SSTAs over the equatorial eastern Pacific (Mong-Ming Lu, personal communication). In this work, however, it is pointed out that there is an intriguing relationship between the characteristics of the local ITY events in the Taiwan area and the ENSO cycles.

The flow of this paper is outlined as follows. In Section 2, the data sets used are presented. The characteristics of annual ITYs, the selection of suitable ENSO index, and the way to reconstruct the mean surface wind field from the pseudo-stress data are described in Section 3. The methodology applied to detect the relationship between two parameters is briefly discussed in Section 4. In Section 5 the main results of this study are reported, while in Section 6 one possible physical explanation of the findings from the percept of mean large-scale circulations. Concluding remarks are then drawn in Section 7.

\section{DATA}

The ITY data set used in this work is provided by Hsiao (1992, his Table 6), whose study was based on historical typhoon reports of the CWB in Taiwan. With their records in Taiwan having been collected since 1897, an ITY at the CWB is defined as 1) a typhoon whose center had passed through Taiwan or the nearby maritime areas within a $200-\mathrm{km}$ limit (about the averaged $10-\mathrm{m} / \mathrm{s}$-wind radius of storm), or 2) one that is beyond the $200-\mathrm{km}$ limit but that results in any near sea-level stations in the Taiwan area recording a maximal mean wind over $10 \mathrm{~m} / \mathrm{s}$ or receiving a total rainfall of over $100 \mathrm{~mm}$ during its influence period (Hsu, 1949 ), or 3) one whose path of center approaches the nearby maritime regions and causes loss of lives and/or great damage to properties on either Taiwan or the nearby maritime areas (one case in 1983), including Kinmen Island (one case in 1973) (Chi 1978). Here, Figure 1 shows the time series of the annual total of ITYs in Taiwan updated to 1993. However, only data from the period of 1949-93 are used for the reason which becomes clear later. It may seem 
that the definition of an ITY in Taiwan thus given is subjective. However, on reevaluation of the records from 1958 to 1987, Hsiao et al. (1989) found only a slight difference (4 out of 101 storms) in the new list of ITYs created with a more objective definition (i.e., according to sea-level pressure, mean wind and precipitation recorded in the near sea-level stations) from the old one. Therefore, the result in this study should not be subject to strong statistical bias.

For comparison and completeness, records of tropical cyclone activities over the WNP (including South China Sea) area are also required. The data are taken from Lander (1994; see his Table 1), which originally came from the Annual Tropical Cyclone Report (ATCR) issued by the Joint Typhoon Warning Center (JTWC) in Guam. The data only cover the period from 1960 to 1991 , however. Note that tropical cyclones include tropical depressions (i.e., maximum wind $\leq 17 \mathrm{~m} / \mathrm{s}$ ), tropical storms (i.e., $17 \mathrm{~m} / \mathrm{s}<$ maximum wind $\leq 34 \mathrm{~m} / \mathrm{s}$ ) and typhoons (i.e., maximum wind $>34 \mathrm{~m} / \mathrm{s}$ ). The ITYs considered in this work include both tropical storms and typhoons. Information about the ENSO cycle is provided by the Long-range Forecast Division of the Japanese Meteorological Agency (LFD/JMA). The JMA has compiled four SST indices, since January 1949, by averaging monthly SSTAs over four different regions mostly located in the equatorial eastern and central Pacific (Figure 2). Focus here is on the SSTA index in the so-called Niño 3 region that covers the area of $4^{\circ} \mathrm{S}-4^{\circ} \mathrm{N}$, $150^{\circ}-90^{\circ} \mathrm{W}$ in that it is supposed to be one of the most representative ENSO indices since it generally covers the core region of the warm pool during the major ENSO events (Rasmusson and Carpenter, 1982).

The computed monthly pseudo-stress anomalies at sea level (actually at $10 \mathrm{~m}$ above) in the 1961-93 period are used as a bridge to link the relationship between the typhoon activities and the ENSO phenomena. The data, which cover the domain of $29^{\circ} \mathrm{S}-29^{\circ} \mathrm{N}$, $124^{\circ} \mathrm{E}-70^{\circ} \mathrm{W}$ with a $2^{\circ} \times 2^{\circ}$ resolution, were compiled by Florida State University (FSU) from ship reports (e.g. Goldenberg and O'Brien 1981). Although this data set only contains the information of lower-level tropospheric circulation, it is the only available data that cover the earliest observations. Since the upper-Jayer circulation (e.g., 200-hpa) is generally in an opposite phase to the lower-level circulation over the tropical region, a good view of the whole general circulation is still permitted over this period.

\section{PRELIMINARY ANALYSIS}

\subsection{Typhoon Activities in Taiwan}

\subsubsection{Interannual and ultra-low-frequency variability}

It is apparent from Figure 1 that there is a pronounced interannual fluctuation in the annual number of ITYs (for shortness, denoted as $\langle T Y\rangle_{\mathrm{tw}}$ ). This can also be understood from the distribution of years categorized with the same $\langle\mathrm{TY}\rangle_{\mathrm{tw}}$ (Figure 3). According to the upper panel, $\langle\mathrm{TY}\rangle_{\mathrm{tw}}$ ranges from none to at most eight in one year. Most years generally record 3-4 ITYs, while the number of years drops considerably when $\langle\mathrm{TY}\rangle_{\mathrm{tw}}$ is beyond 5 events, or when it is below 2 . The overall shape of the distribution in the lower panel (1949-93) is somehow similar to the longer record (1897-93), except that it is less like a normal distribution. This may be caused by either sample bias or a long-term trend. From the perspective of a normal-distribution. Figure 3(b) indicates that the number of years with $\langle\mathrm{TY}\rangle_{\mathrm{tw}}=1,3$ or 5 , respectively, are slightly higher, while those with $\langle\mathrm{TY}\rangle_{\mathrm{tw}}=2$, or 4 , 
(a)

NINO_West

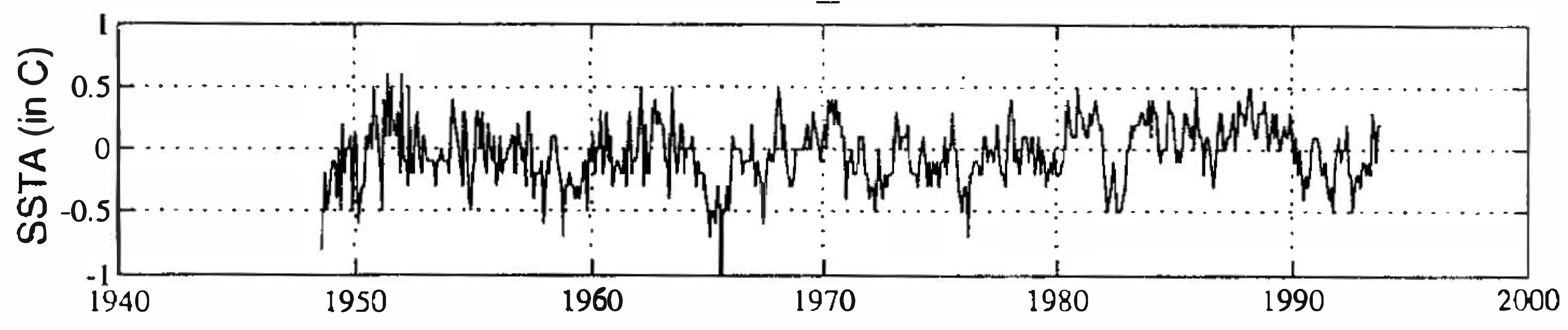

(b) NINO_4

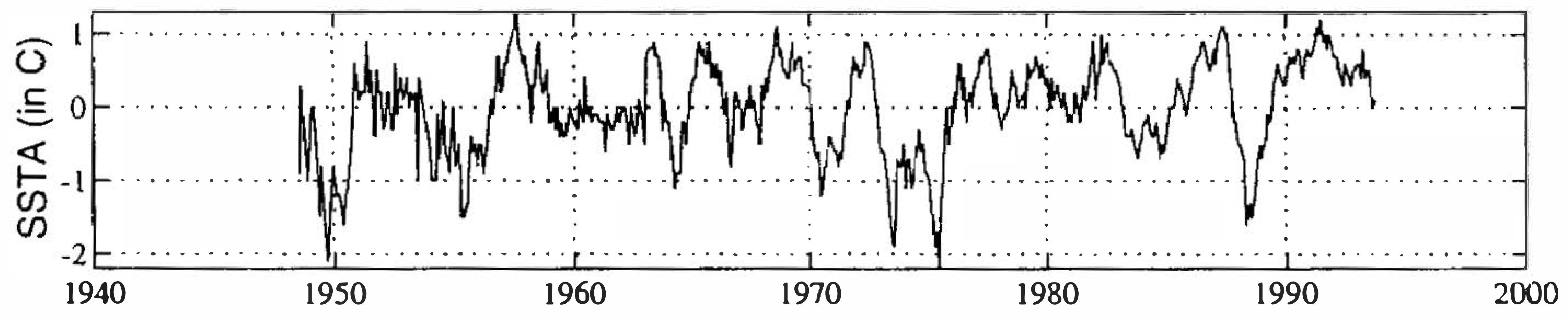

(c)

NINO_3

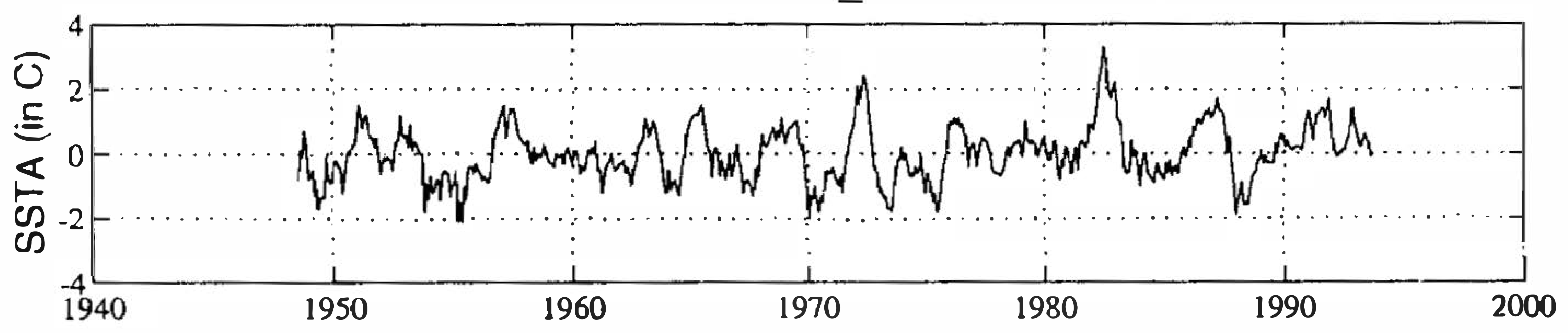

(d)

NINO_1+2

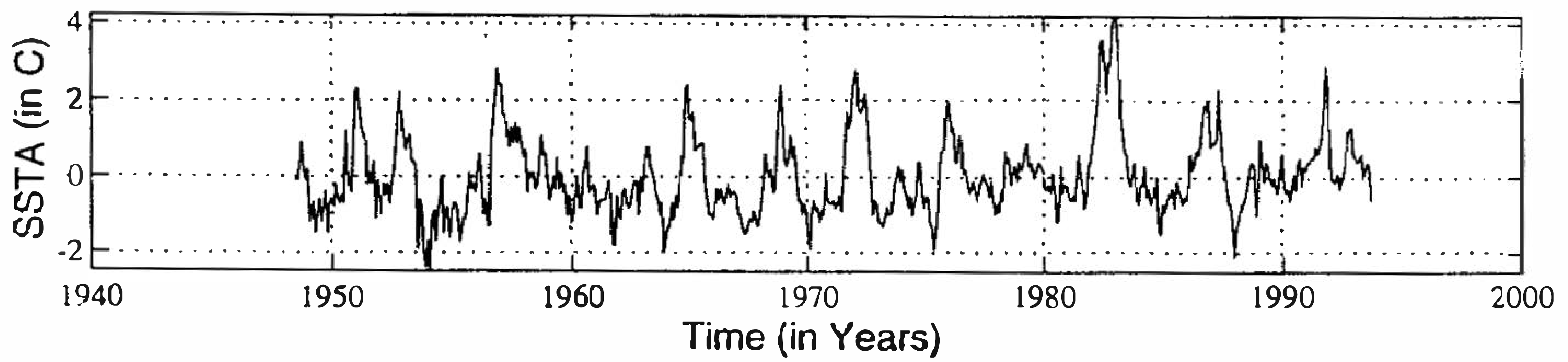

Fig. 2. Time series of the JMA/LFD El Niño (SSTA) indices in (a) the Niño West region $\left(0^{\circ}-14^{\circ} \mathrm{N}, 130^{\circ}-150^{\circ} \mathrm{E}\right)$, (b) the $\mathrm{Ni} \tilde{n} \mathrm{o} 4$ region $\left(4^{\circ} \mathrm{S} 4^{\circ} \mathrm{N}\right.$, $\left.160^{\circ} \mathrm{E} 150^{\circ} \mathrm{W}\right)$, (c) the $\mathrm{Ni}$ o 3 region $\left(4^{\circ} \mathrm{S} 4^{\circ} \mathrm{N}, 150^{\circ}-90^{\circ} \mathrm{W}\right)$, and (d) the Niño $1+2$ region $\left(0^{\circ}-10^{\circ} \mathrm{S}, 90^{\circ}-80^{\circ} \mathrm{W}\right)$.

respectively, are a little fewer than anticipated for the period of 1949-93. The long-term trend seems to exist as observed from Figure 1. The periods of mid-1900s, mid-1920s, early 60s and 80s appear to have more $\left\langle\mathrm{TY}>_{\mathrm{tw}}\right.$, while other periods show the opposite. It can also be noted that there were more $\left\langle\right.$ TY $>_{\text {tw }}$ before 1930, but fewer after 1960.

In this study, the years with $\langle\mathrm{TY}\rangle_{\mathrm{tw}} \geq 5$ are classified as above-normal years, whereas those with $\langle\mathrm{TY}\rangle_{\mathrm{tw}} \leq 2$ below-normal years. Such a definition can be justified on the ground that the probabilities of $\langle\mathrm{TY}\rangle_{\mathrm{tw}}$ being less than 3 or greater than 5 are roughly equal $(\sim 30 \%)$, as deduced from the time series (Figure 4). With this classification in mind, the shifts toward lower $\langle\mathrm{TY}\rangle_{\mathrm{tw}}$ in each category (as suggested by the comparison between both panels of 
(a) Distribution of Annual Invaded Typhoons in Taiwan (1897-1993)

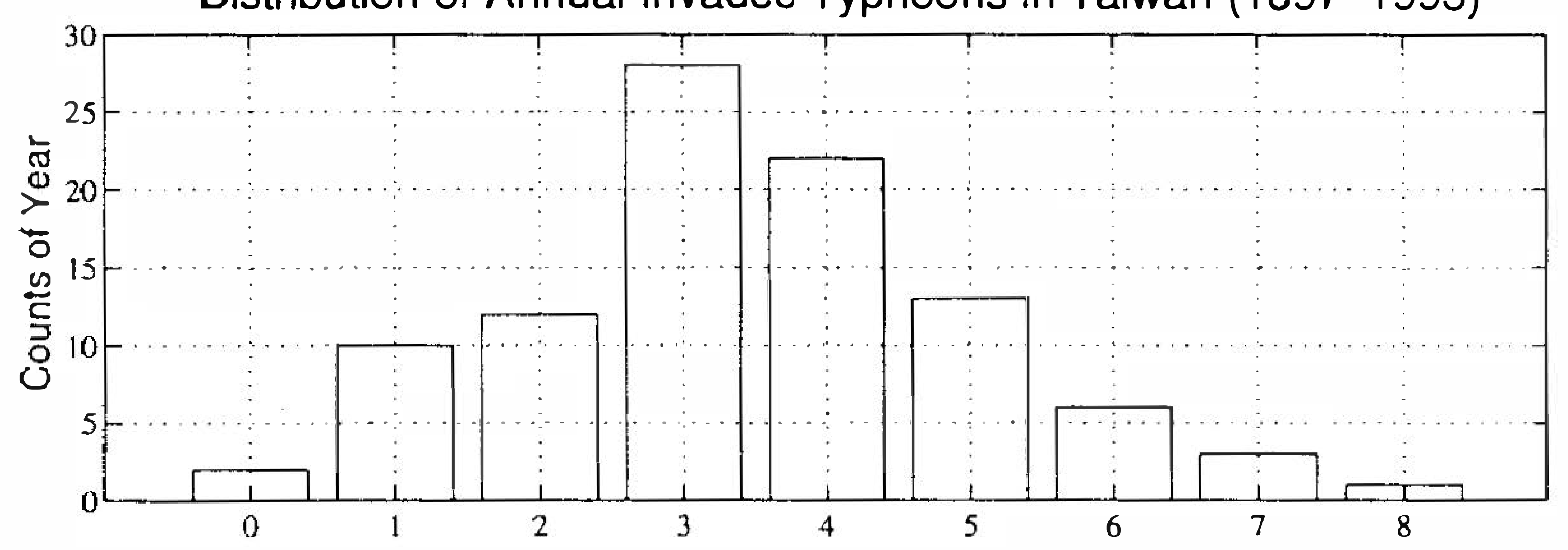

(b) 1949-93

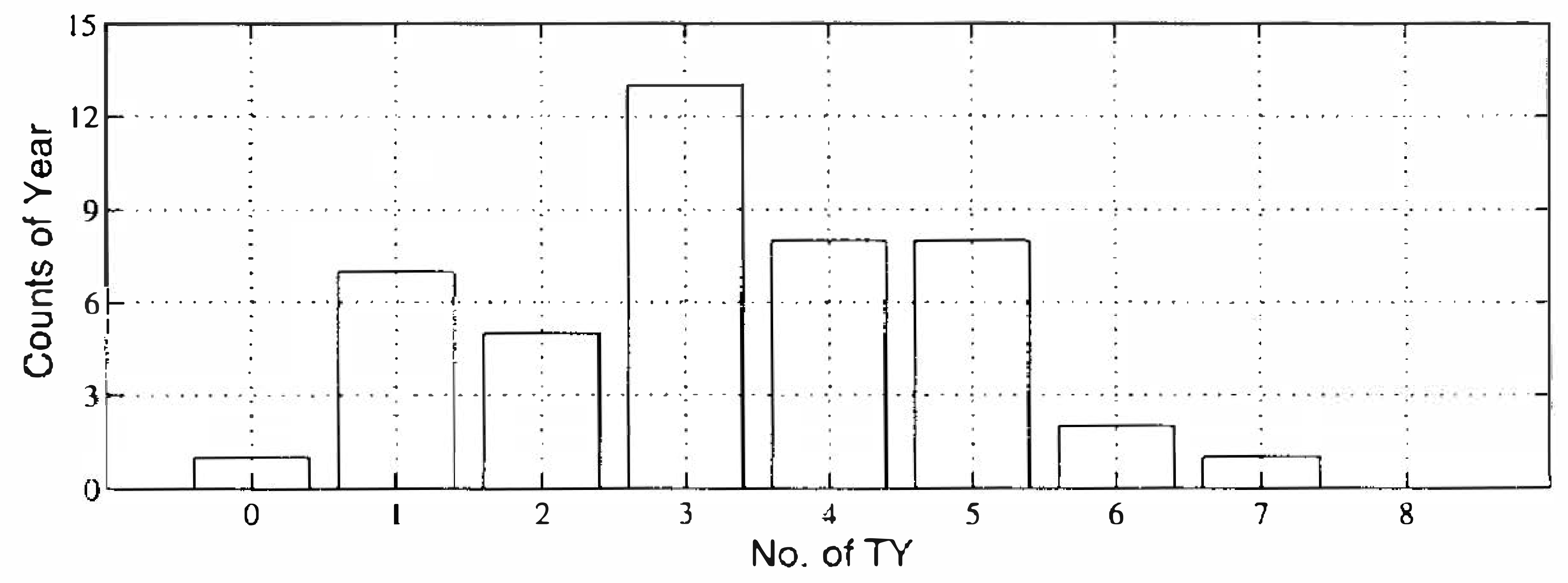

Fig. 3. Distribution of typhoon activities in Taiwan in terms of the annual total in the periods of (a) 1897-1993 and (b) 1949-93.

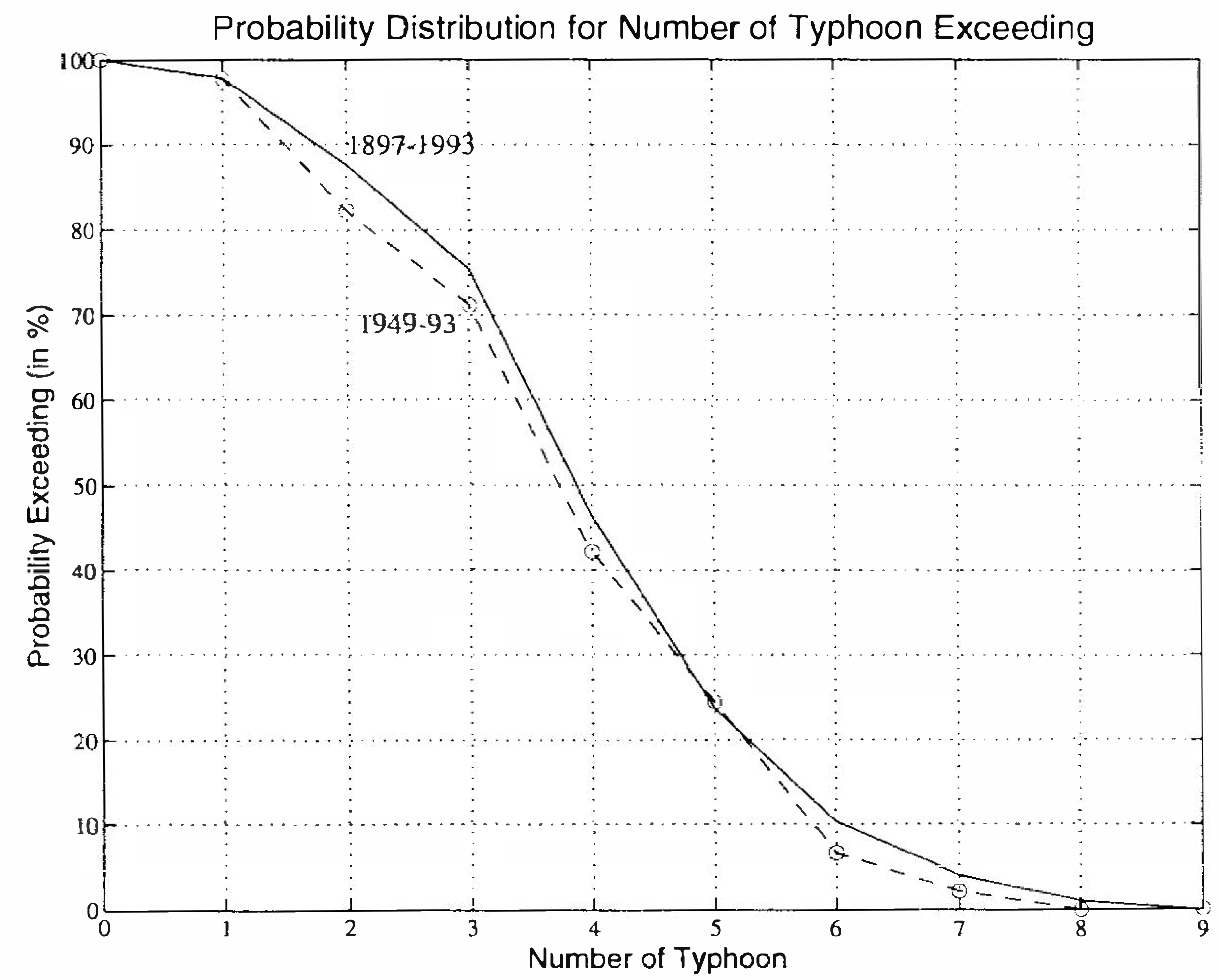

Fig. 4. Probability distribution (in $\%)$ for $\langle\mathrm{TY}\rangle_{\mathrm{tw}}$ with no less than $\mathrm{n}(=0,1, \ldots$, 8 ) in the periods of 1897-1993 (solid line) and 1949-93 (dashed line with open circles). 
Figure 3) should be viewed as further evidence of the somewhat decreasing long-term trend in the annual total number of ITYs in Taiwan. Nevertheless, such a trend may be artificial on account of the earlier observations being less reliable.

\subsubsection{Dynamical relevance?}

It is expected that there would be more $\langle\mathrm{TY}\rangle_{\text {tw }}$ in those years when with more tropical storms over the WNP. If this is true, what we really need to look at is just the relationship between the more large-scale typhoon activities over the WNP and the ENSO cycle. Several studies have explored the existence of such a correlation (e.g., Ramage and Hori 1981; Chan 1985, 1990; Dong, 1988; Li, 1988; Lander 1994), and it is unanimously accepted that a seesaw pattern for the location of storm formation is closely correlated to the ENSO events. In other words, the genesis region of tropical cyclones over the WNP shifts eastward when the Southern Oscillation index (SOI) is low and the SSTs in the equatorial central and eastern Pacific are warmer than normal, while it shifts westward when the SOI is high and the SSTs are colder than normal (see e.g., Lander 1994). Nevertheless, the issue on the annual frequency of typhoon activity has not yet been settled. To illustrate, the annual report of the JMA (1991) suggested that El Niño events generally correspond to a decrease in the annual totals of tropical storms in the WNP area. The result of Wu and Lau (1992) also indicated a significant ENSO-related signal in the annual total of simulated tropical cyclones from a 15-year (1962-76) GCM simulation with observed SSTs as boundary conditions. On the other hand, Ramage and Hori (1981) and Lander (1994) did not find any significant correlation between tropical storm frequency and ENSO. Regardless of the above-mentioned debate, Table 1 suggests that the deciding factor as to how the tendency of the ITYs in Taiwan would be (i.e., more, normal, or less) is not just associated with the annual total number of tropical storms occurring over the WNP (denoted as $\langle\mathrm{TY}\rangle_{\mathrm{wnp}}$ ). From the table, the years with above-normal $\langle\mathrm{TY}\rangle_{\text {tw }}$ do in general tend to be associated with higher $\langle\mathrm{TY}\rangle_{\mathrm{wnp}}$ (say $\geq 27$ ), and vice versa. It is however not always true, as one would notice, that several years (say 1989, 1972 and 1964) with more $\langle\text { TY }\rangle_{\text {wnp }}$ did not result in more ITYs in Taiwan but in fact the opposite occurred. Such an observation is not surprising since whether an individual typhoon over the WNP influences the Taiwan area or not strongly depends on its track, which is determined mostly by the background steering flow and the transient extratropical upperlayer trough. Therefore, by focusing on the annual frequency of the ITYs in Taiwan, not only are the large-scale dynamical conditions favorable to the formation of tropical storms over the WNP considered, but the large-scale background flow that is preferential to direct typhoons which passing nearby Taiwan is also. Since the atmospheric response associated with the underlying SST boundary forcing is generally reflected in the mean large-scale circulation, only the mean large-scale steering circulation regarding to the typhoon tracking issue is emphasized.

\subsection{ENSO Indices}

Since the purpose of this study is to relate the annual activities of typhoons to tropical SSTA conditions over the equatorial eastern Pacific, it is obvious that a suitable yearly parameter from the monthly Niño 3 index needs to be compiled. The easiest one is perhaps to choose the yearly average of the SSTA index as an ENSO parameter. However, by doing so, the ENSO signal would be greatly reduced since the extreme phases generally do not persist throughout the whole calender year. Therefore, it is worth examining the time series of the SSTA first in order to select a representative parameter. 
Table 1. Ranking of years according to the corresponding annual total of tropical storms over the WNP $\left.(<\mathrm{TY}\rangle_{\text {wnp }}\right)$ in the period of 1960-91. Also indicated in the fourth column are the associated categories (classified as + above-normal, and - below-normal) of the annual total of ITYs in Taiwan $\left(\langle\mathrm{TY}\rangle_{\mathrm{tw}}\right)$ in each year.

\begin{tabular}{|c|c|c|c|}
\hline Rank & Years & $<\mathrm{TY}\rangle_{\text {wnp }}$ & Category of $\langle\mathrm{TY}\rangle_{\mathrm{tw}}$ \\
\hline 1 & 1964 & 39 & - \\
\hline 2 & 1971 & 35 & \\
\hline 2 & 1967 & 35 & \\
\hline 4 & 1965 & 34 & \\
\hline 5 & 1974 & 32 & \\
\hline 6 & 1990 & 31 & + \\
\hline 6 & 1989 & 31 & - \\
\hline 6 & 1961 & 31 & + \\
\hline 9 & 1991 & 30 & \\
\hline 9 & 1972 & 30 & - \\
\hline 9 & 1966 & 30 & \\
\hline 9 & 1962 & 30 & + \\
\hline 13 & 1981 & 28 & + \\
\hline 13 & 1978 & 28 & \\
\hline 15 & 1986 & 27 & \\
\hline 15 & 1984 & 27 & + \\
\hline 15 & 1968 & 27 & \\
\hline 15 & 1960 & 27 & + \\
\hline 19 & 1988 & 26 & - \\
\hline 19 & 1985 & 26 & + \\
\hline 19 & 1982 & 26 & \\
\hline 22 & 1976 & 25 & - \\
\hline 22 & 1963 & 25 & - \\
\hline 24 & 1987 & 24 & \\
\hline 24 & 1980 & 24 & \\
\hline 24 & 1970 & 24 & - \\
\hline 27 & 1983 & 23 & - \\
\hline 27 & 1979 & 23 & - \\
\hline 29 & 1973 & 21 & - \\
\hline 30 & 1975 & 20 & \\
\hline 31 & 1977 & 19 & \\
\hline 31 & 1969 & 19 & \\
\hline
\end{tabular}

Figure 5 shows the evolution of the five-month running-mean SSTA index at Niño 3 within a two-year window. It is noted that a significant magnitude of warm/cold phases tends to occur from June of one year through February of the following. The maxima were generally reached in the period of September through December. Based on this observation, it is reasonable to use the September-December mean of each year as the desired ENSO 


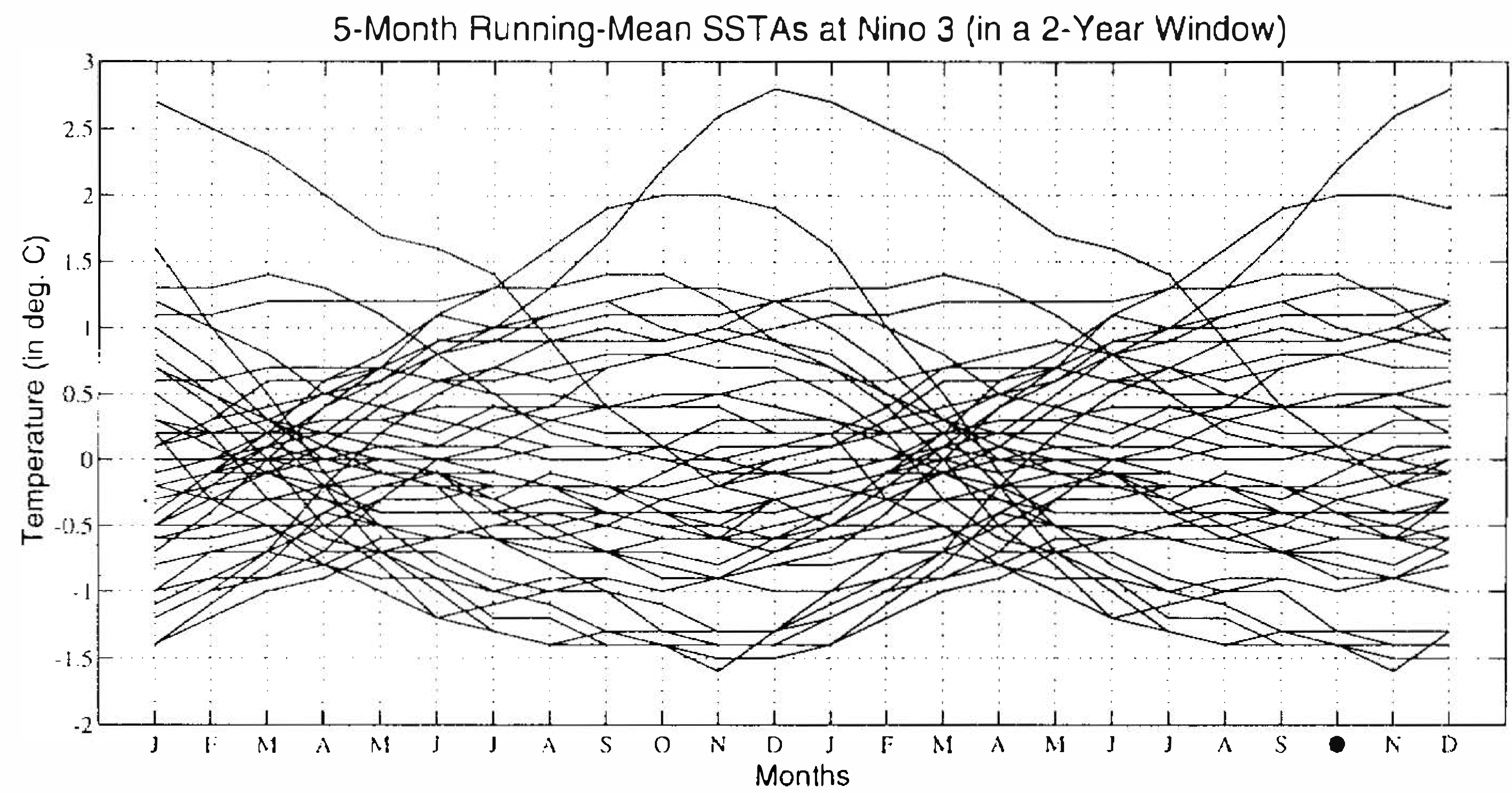

Fig. 5. Time series of the 5-month running-mean SSTAs in the Niño 3 region within a two-year window from 1949 to 1993.

index, which is referred to as $\langle\text { SSTA }\rangle_{\text {sond }}$. The only exception is perhaps the extremely strong ENSO event that occurred in the winter of 1982-83. During that episode, the warmest phase arrived in December 1982. However, the period with SSTA higher than $1{ }^{\circ} \mathrm{C}$ persisted from June 1982 through July 1983 for more than a one-year span. As a result, the typhoon season in 1983 might have actually been significantly affected by the ENSO event although $\langle\mathrm{SSTA}\rangle_{\text {sond }}$ of 1983 was merely $-0.175^{\circ} \mathrm{C}$. Table 2 gives the compiled $\langle\mathrm{SSTA}\rangle_{\text {sond }}$ for each year.

\subsection{Derivation of Weighted-Wind Anomalies}

The FSU pseudo-stress vector is defined as

$$
\tau=\left(\tau_{x}, \tau_{y}\right)=(\bar{W} u, \bar{W} v),
$$

where $\tau$ denotes the pseudo-stress, subscripts indicate the $x, y$ components respectively, $W$ is the wind speed, and $u, v$ are zonal and meridional wind components, respectively (see Goldenberg and O'Brien 1981). The over bar stands for the monthly mean. Therefore, the pseudo-stress field can be used to substitute the horizontal wind field if the circulation is one's main interest. To also examine the corresponding divergence field, it is better to revert the FSU pseudo-stress into a field that has a unit equivalent to velocity.

Assuming that the nonlinear effect among different temporal scales can be neglected, the monthly' mean wind speed on each grid point can be estimated as:

$$
\bar{W} \approx W=\left(\left\|\tau^{2}\right\|\right)^{1 / 4} .
$$

As such, the monthly-mean horizontal wind field can be reconstructed by:

$$
(\bar{u}, \bar{v})=\left(\tau_{x}, \tau_{y}\right) / W .
$$

In this study, Eqs. (2) and (3) were applied to the FSU monthly pseudo-stress anomalies to recover the monthly wind anomalies. Prior to this procedure, both temporal and spatial 
Table 2. Computed $\langle\mathrm{SSTA}\rangle_{\text {sond }}\left(\right.$ in ${ }^{\circ} \mathrm{C}$ ) in the period of $1949-93$.

\begin{tabular}{|c|c|}
\hline Years & $<\operatorname{SSTA}>_{\text {sond }}\left({ }^{\circ} \mathrm{C}\right)$ \\
\hline 1949 & -1.3 \\
\hline 1950 & -0.675 \\
\hline 1951 & 0.975 \\
\hline 1952 & -0.25 \\
\hline 1953 & 0.425 \\
\hline 1954 & -1.025 \\
\hline 1955 & -1.675 \\
\hline 1956 & -0.8 \\
\hline 1957 & 0.975 \\
\hline 1958 & -0.125 \\
\hline 1959 & -0.15 \\
\hline 1960 & -0.4 \\
\hline 1961 & -0.675 \\
\hline 1962 & -0.675 \\
\hline 1963 & 0.775 \\
\hline 1964 & -1.025 \\
\hline 1965 & 1.325 \\
\hline 1966 & -0.55 \\
\hline 1967 & -0.95 \\
\hline 1968 & 0.425 \\
\hline 1969 & 0.875 \\
\hline 1970 & -1.425 \\
\hline 1971 & -0.95 \\
\hline 1972 & 2.025 \\
\hline 1973 & -1.525 \\
\hline 1974 & -0.575 \\
\hline 1975 & -1.4 \\
\hline 1976 & 0.975 \\
\hline 1977 & 0.25 \\
\hline 1978 & -0.2 \\
\hline 1979 & 0.525 \\
\hline 1980 & 0.1 \\
\hline 1981 & -0.025 \\
\hline 1982 & 2.425 \\
\hline 1983 & -0.175 \\
\hline 1984 & -0.525 \\
\hline 1985 & -0.425 \\
\hline 1986 & 0.9 \\
\hline 1987 & 1.375 \\
\hline 1988 & -1.4 \\
\hline 1989 & -0.25 \\
\hline 1990 & 0.15 \\
\hline 1991 & 0.9 \\
\hline 1992 & 0.025 \\
\hline 1993 & 0.4 \\
\hline
\end{tabular}


smoothing were applied to the original pseudo-stress data since the seasonal-scale, largescale circulation is of prime interest here. The temporal filtering is a 3-point smoothing with weights of $(1,2,1) / 4$. A 9-point spatial smoothing is employed with weights equivalent to applying a filter of $(1,2,1) / 4$ simultaneously in both the $x$ and $y$ directions.

\section{METHODOLOGY}

\subsection{Linear Correlation Analysis}

The purpose of this study is first to verify whether the $\langle\mathrm{TY}\rangle_{\mathrm{tw}}$ can be related to the SSTAs that occurred over the equatorial eastern Pacific. The simplest way to identify any linear relation between two variables is to calculate their correlation coefficient. However, if the relation between two parameters is not linear, it cannot be detected in this manner, as, it is shown later, is the case in this study. A more general analysis is thus desired to reveal the association between two variables.

\subsection{Contingency Table Analysis}

Although $\langle\mathrm{TY}\rangle_{\text {tw }}$ is a discrete integer, it can always be classified into different categories defined by certain ranges. This is also true for the SSTA index. Therefore, if there is any association between the two parameters, it can be determined by examining the distribution of data in each category. Such an analysis is the so-called Contingency Table Analysis (CTA) with the significance of the association measured by the $X^{2}$ test.

Suppose that it is decided to have $I$ categories in the SSTA index, and $J$ categories in $<\mathrm{TY}>_{\text {tw }}$. The $\mathrm{X}^{2}$ can thus be calculated as:

$$
X^{2}=\sum_{i, j} \frac{\left(N_{i, j}-n_{i, j}\right)^{2}}{n_{i, j}},
$$

where

$$
n_{i, j}=\frac{N_{i} N_{j}}{N}
$$

Note that $N_{i, j}$ is the number of observed data points that fall into both the $i$-th category of the SSTA and the $j$-th category of $\langle\mathrm{TY}\rangle_{\mathrm{tw}}, n_{i, j}$ is the expected value of $N_{i, j}, N_{i}$ denotes the number of data points that belongs to the $i$-th category of SSTA, $N_{j}$ represents the number of data points that belongs to the $j$-th category of $\langle\mathrm{TY}\rangle_{\mathrm{tw}}$, and $N$ is the total number of data points considered.

The strength of the association between two variables is measured either by the Cramers $V$, which is defined as:

$$
V=\sqrt{\frac{X^{2}}{N \cdot \min (I-1, J-1)}},
$$

or by the contingency coefficient $C$, where:

$$
C=\sqrt{\frac{X^{2}}{X^{2}+N}}
$$


Unlike the linear correlation analysis, the CTA can also detect a nonlinear association. (For detailed information about the CTA, see e.g., Downie and Heath, 1965)

\section{RESULTS}

To envision any possible relationship between $\langle\mathrm{TY}\rangle_{\mathrm{tw}}$ and the ENSO cycles, first the two parameters are put together as in Figure 6. This shows that the warm SSTA events tend to associate with a low $\left\langle\mathrm{TY}>_{\mathrm{tw}}\right.$, except in 1969,1986 and 1987. On the other hand, the cold events do not necessarily correspond to an increase in $\langle\mathrm{TY}\rangle_{\mathrm{tw}}$, as would be expected from a linear perception. For example, the colder-than-normal years in early-, mid-60s and mid-80s do associate with the above-normal $\langle\mathrm{TY}\rangle_{\mathrm{tw}}$; however, the cold events, on the other hand, in 1955, 1964, 1970, 1973 and 1988 correspond to a reduction in $\langle\mathrm{TY}\rangle_{\mathrm{tw}}$. Therefore, it appears that there is no simple linear correlation between the annual total ITYs in Taiwan and the ENSO cycle. The calculation of the correlation coefficient $(\mathrm{cc}=-0.054)$, as expected, confirms that there is virtually no linear relation between those two parameters.

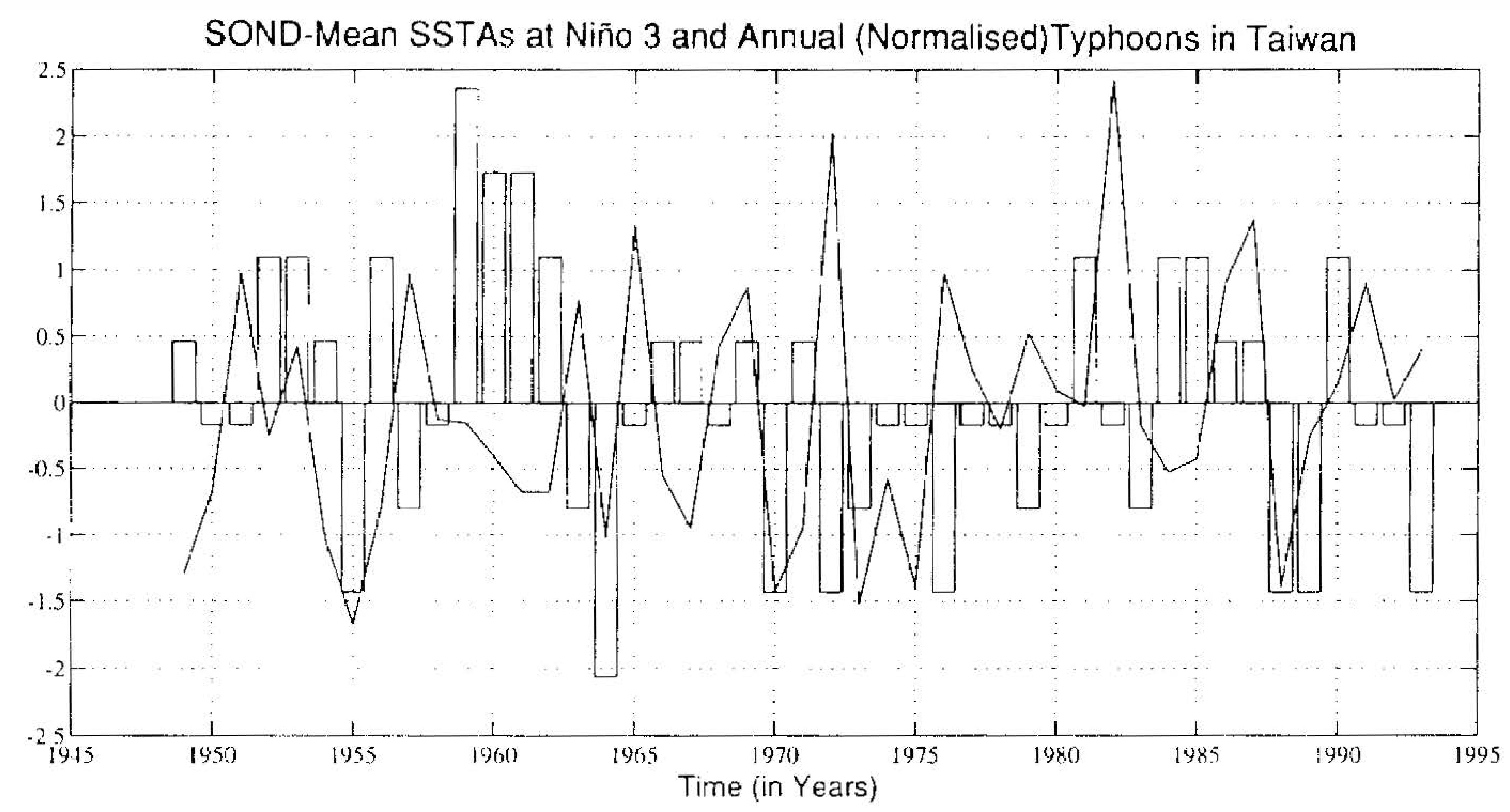

Fig. 6. Time series of yearly $<$ SSTA $>_{\text {sond }}$ in the Niño 3 region (solid line) and the normalized $\langle\mathrm{TY}\rangle_{\text {tw }}$ (bar) in the period of 1949-93.

However, it is noted that the reduction of $\langle\mathrm{TY}\rangle_{\text {tw }}$ in below-normal SSTA cases seems to correspond mostly to a strong cold event (e.g. in those years mentioned above). To illustrate more clearly this finding, the data have been ranked in terms of $\langle\mathrm{TY}\rangle_{\text {tw }}$ in descending order, and the distribution of SSTA index has been examined accordingly (Table 3). It is apparent that the above-normal years (with $\langle\mathrm{TY}\rangle_{\mathrm{tw}} \geq 5$ ) generally correspond to slightly cooler-thannormal years, except in 1990 (with a near normal SSTA index) and 1953 (a slightly warm SSTA). By excluding those two years, the mean SSTA index for the above-normal years was about $-0.436\left({ }^{\circ} \mathrm{C}\right)$. On the other hand, the below-normal years (with $\langle\mathrm{TY}\rangle_{\mathrm{tw}} \leq 2$ ) tend to associate with either warm years or very cold years (except in 1983 and 1989). Notice that in those two years, one case (1983) comes after an extremely strong warm episode (1982), while the other (1989) follows after a strong La Niña event (1988). The averaged $<$ SSTA $>_{\text {sond }}$ for cold years with a below-normal number of ITYs is calculated to be $-1.068\left({ }^{\circ} \mathrm{C}\right)$. The value becomes $-1.41\left({ }^{\circ} \mathrm{C}\right)$ by discarding the two exceptional years. It is thus suggested that 
Table 3. Ranking of years (1949-93) according to the $\langle\mathrm{TY}\rangle_{\text {tw }}$ of each year. The corresponding $<\mathrm{SSTA}\rangle_{\text {sond }}\left({ }^{\circ} \mathrm{C}\right)$ is also given in the last column.

\begin{tabular}{|c|c|c|c|}
\hline Rank & Year & $<\mathrm{TY}\rangle_{\text {tw }}$ & $<$ SSTA $\rangle_{\text {sond }}$ \\
\hline 1 & 1959 & 7 & -0.150 \\
\hline 2 & 1961 & 6 & -0.675 \\
\hline 3 & 1960 & 6 & -0.400 \\
\hline 4 & 1990 & 5 & 0.150 \\
\hline 5 & 1985 & 5 & -0.425 \\
\hline 6 & 1984 & 5 & -0.525 \\
\hline 7 & 1981 & 5 & -0.025 \\
\hline 8 & 1962 & 5 & -0.675 \\
\hline 9 & 1956 & 5 & -0.800 \\
\hline 10 & 1953 & 5 & 0.425 \\
\hline 11 & 1952 & 5 & -0.250 \\
\hline 12 & 1987 & 4 & 1.375 \\
\hline 13 & 1986 & 4 & 0.900 \\
\hline 14 & 1971 & 4 & -0.950 \\
\hline 15 & 1969 & 4 & 0.875 \\
\hline 16 & 1967 & 4 & -0.950 \\
\hline 17 & 1966 & 4 & -0.550 \\
\hline 18 & 1954 & 4 & -1.025 \\
\hline 19 & 1949 & 4 & -1.300 \\
\hline 20 & 1992 & 3 & 0.025 \\
\hline 21 & 1991 & 3 & 0.900 \\
\hline 22 & 1982 & 3 & 2.425 \\
\hline 23 & 1980 & 3 & 0.100 \\
\hline 24 & 1978 & 3 & -0.200 \\
\hline 25 & 1977 & 3 & 0.250 \\
\hline 26 & 1975 & 3 & -1.400 \\
\hline 27 & 1974 & 3 & -0.575 \\
\hline 28 & 1968 & 3 & 0.425 \\
\hline 29 & 1965 & 3 & 1.325 \\
\hline 30 & 1958 & 3 & -0.125 \\
\hline 31 & 1951 & 3 & 0.975 \\
\hline 32 & 1950 & 3 & -0.675 \\
\hline 33 & 1983 & 2 & -0.175 \\
\hline 34 & 1979 & 2 & 0.525 \\
\hline 35 & 1973 & 2 & -1.525 \\
\hline 36 & 1963 & 2 & 0.775 \\
\hline 37 & 1957 & 2 & 0.975 \\
\hline 38 & 1993 & 1 & 0.400 \\
\hline 39 & 1989 & 1 & -0.250 \\
\hline 40 & 1988 & 1 & -1.400 \\
\hline 41 & 1976 & 1 & 0.975 \\
\hline 42 & 1972 & 1 & 2.025 \\
\hline 43 & 1970 & 1 & -1.425 \\
\hline 44 & 1955 & 1 & -1.675 \\
\hline 45 & 1964 & 0 & -1.025 \\
\hline
\end{tabular}


the relation between $\langle\mathrm{TY}\rangle_{\mathrm{tw}}$ and the SSTA index is a nonlinear one, and one such that $\langle\mathrm{TY}\rangle_{\mathrm{tw}}$ is low when the SSTA is warmer than usual, but high when the SSTA is slightly cooler than normal. However, when the SSTA becomes too cold (say roughly $1.0^{\circ} \mathrm{C}$ below normal), $\langle\mathrm{TY}\rangle_{\mathrm{tw}}$ in fact would be reduced, instead of increased.

To further demonstrate the nonlinear relationship, the scatterplot of $\langle\mathrm{TY}\rangle_{\mathrm{tw}}$ versus $<$ SSTA $>_{\text {sond }}$ was graphed in Figure 7 . It is apparent that the warm years are generally associated with $\langle\mathrm{TY}\rangle_{\mathrm{tw}} \leq 4$, which is also true for years with SSTA $1.0\left({ }^{\circ} \mathrm{C}\right)$ below normal. On the other hand, the cool years [SSTA below normal, yet not extremely cold $(\geq$ $-1.0^{\circ} \mathrm{C}$ )] are roughly associated with $\langle\mathrm{TY}\rangle_{\mathrm{tw}} \geq 3$. With this diagram as a reference, the data points may be classified into three categories in terms of the SSTA index, i.e., the warm years $\left(\mathrm{SSTA} \geq 0{ }^{\circ} \mathrm{C}\right)$, the cool years $\left(-1.0 \leq \mathrm{SSTA}<0^{\circ} \mathrm{C}\right)$, and the cold years $\left(\mathrm{SSTA}<-1.0^{\circ} \mathrm{C}\right)$. (In fact, this has already been done in previous discussions here.) Together with previous definitions of above-, normal-, and below-year in terms of $\langle\mathrm{TY}\rangle_{\mathrm{tw}}$, a contingency table can be formed as listed in Table 4. From this table, it is evident that the majority of cold years are associated with below-normal $\langle\mathrm{TY}\rangle_{\mathrm{tw}}, 50 \%$ of the cool years are with above-normal $\langle\mathrm{TY}\rangle_{\mathrm{tw}}$, while more than $50 \%$ of the warm years mostly correspond to a normal range of ITYs in Taiwan. The test, as formulated in (4), indicates the association between the SSTA index, and $\langle\mathrm{TY}\rangle_{\mathrm{tw}}$ is very significant (surpassed $99 \%$ confidence level). The strength of the association is 0.4 as measured by Cramers $V(6)$, or 0.49 by the contingency coefficient $C$ (7).

SOND-Mean SSTAs at Niño 3 and Annual Totals of Invaded Typhoon in Taiwan

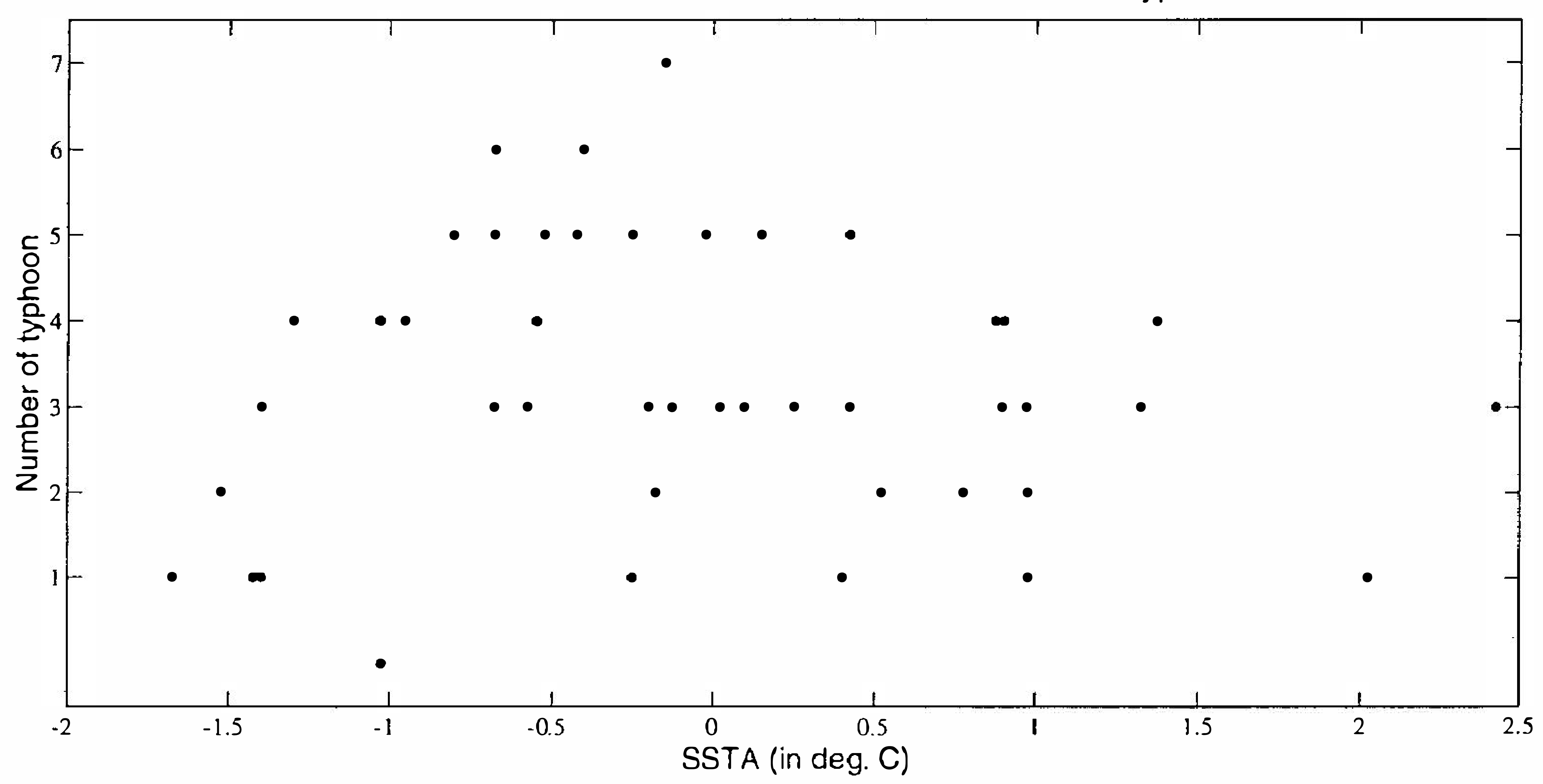

Fig. 7. Scatterplot for $\langle\mathrm{TY}\rangle_{\mathrm{tw}}$ versus $\langle\mathrm{SSTA}\rangle_{\text {sond }}$ in the Niño 3 region.

From these points, it is concluded that the annual total ITYs in Taiwan is related to the SSTAs over the equatorial eastern Pacific. The association between the two parameters is not a simple linear correspondence, but, on the contrary, a rather nonlinear one. It appears that there are fewer $\langle\mathrm{TY}\rangle_{\mathrm{tw}}$ in warm years, whereas there are more in cool years. However, when the SSTA gets too cold, instead of being enhanced, the $\langle\mathrm{TY}\rangle_{\mathrm{tw}}$ is actually severely reduced. It thus seems that there is a threshold, or a turning point in below-normal SSTAs that reverses the correlation between the SSTA index and $\langle\mathrm{TY}\rangle_{\mathrm{tw}}$. 
Table 4. Contingency Table of the years that have been classified with their corresponding $\langle\mathrm{TY}\rangle_{\mathrm{tw}}$ and $\langle\mathrm{SSTA}\rangle_{\text {sond }}\left({ }^{\circ} \mathrm{C}\right)$. (See text for detailed definitions of the classifications.) All values in each column are relative percentages (\%) with respect to the subtotal in the bottom row. The percentage values of the bottom row are in turns with respect to the grand total (i.e., the cell indicated by *). The numbers in parentheses are original counts of years that fall into each of the particular classification.

\begin{tabular}{c|c|c|c|c}
\hline \hline & Cold & Cool & Warm & Subtotal \\
\hline Above & $0(0)$ & $50(9)$ & $10.5(2)$ & $24.4(11)$ \\
\hline Normal & $37.5(3)$ & $38.9(7)$ & $57.9(11)$ & $46.7(21)$ \\
\hline Below & $62.5(5)$ & $11.1(2)$ & $31.6(6)$ & $28.9(13)$ \\
\hline Subtotal & $17.8(8)$ & $40(18)$ & $42.2(19)$ & $100(45)^{*}$ \\
\hline
\end{tabular}

\section{PHYSICAL EXPLANATION}

In the previous section, a statistical association has been identified between the tropical SSTAs and the annual number of ITYs in Taiwan. It is speculated that there may exist a certain dynamical linkage between these two parameters, and the data indicated that they are indeed related to each other.

Since many observational and modeling studies suggest that the atmospheric responses are quite different to various equatorial SSTA conditions, it is reasonable to assume that the tropical SSTAs could influence the interannual variation in $\langle\mathrm{TY}\rangle_{\mathrm{tw}}$ through the mean large-scale circulation over the WNP associated with the ENSO cycle. To explore such a possibility, it is therefore instructive to examine the composite circulations under different SSTA and $\langle\mathrm{TY}\rangle_{\mathrm{tw}}$ conditions.

To address the main concerns of this study, the composites of three clusters, namely the cold years with below-norrnal $\langle\mathrm{TY}\rangle_{\text {tw }}(1988,1973,1970,1964)$, the cool years with abovenormal $\left\langle\right.$ TY $>_{\text {tw }}(1985,1984,1981,1962,1961)$, and the warm years with below-normal $\langle\text { TY }\rangle_{\text {tw }}(1979,1976,1972,1963)$ are highlighted. For easy reference, the three groups are referred to as COLD years, COOL years and WARM years. With the FSU pseudo-stress data starting in 1961, it is therefore not possible to include cases prior to 1960 in each group. However, it is the only data set covering the earliest observation that could be found, as mentioned in Section 2, so as to have as many cases in each cluster as possible. Another point to keep in mind is that the year 1993 is not included in the WARM composite due to its different evolution toward the end of the calendar year from that of other years that have been chosen.

In Figure 8, the mean composite circulations for COLD years are shown in (a) the early season (AMJ) (b) the main season (JAS), and (c) the late season (ON). It is noted that in the main season a huge anti-cyclonic circulation with a large-scale divergence field is located near $\left(20^{\circ} \mathrm{N}, 135^{\circ} \mathrm{E}\right)$. It covers the most of the WNP area and extends eastward to about $160^{\circ} \mathrm{E}$. Since the region is approximately the climatological location of tropical stom formation (see e.g. Lander 1994, his Figure 4), such an unfavorable large-scale dynamical condition 


\section{(a) AMJ}

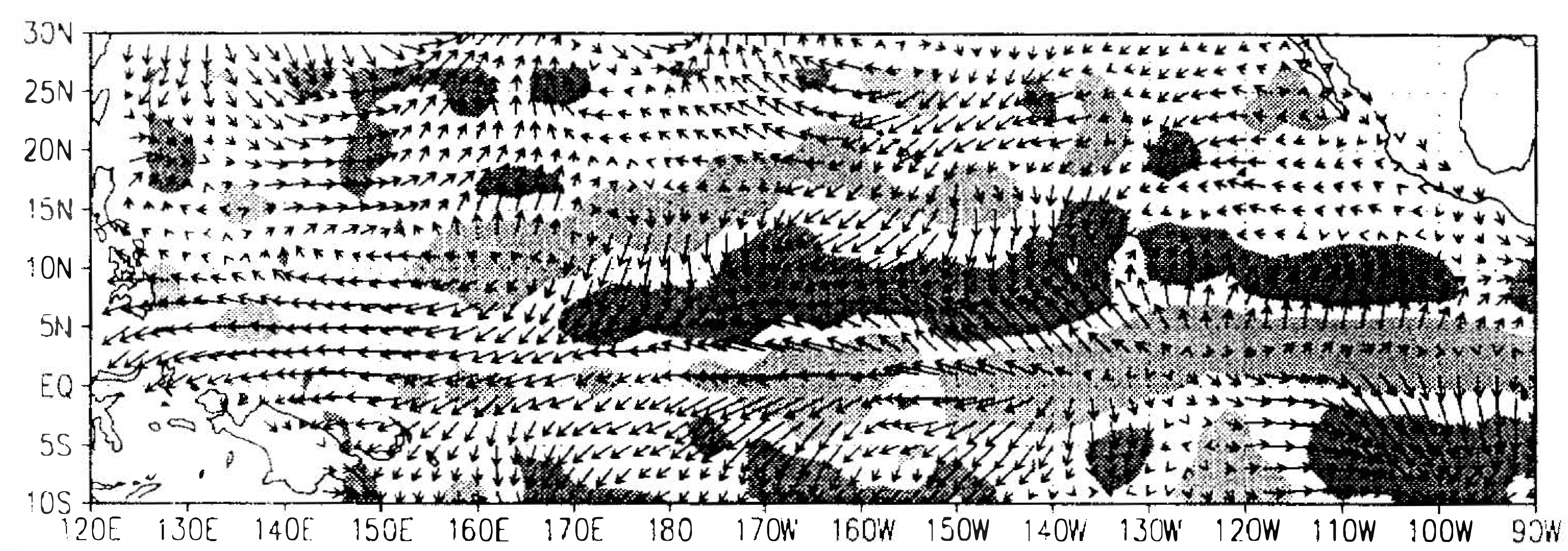

(b)

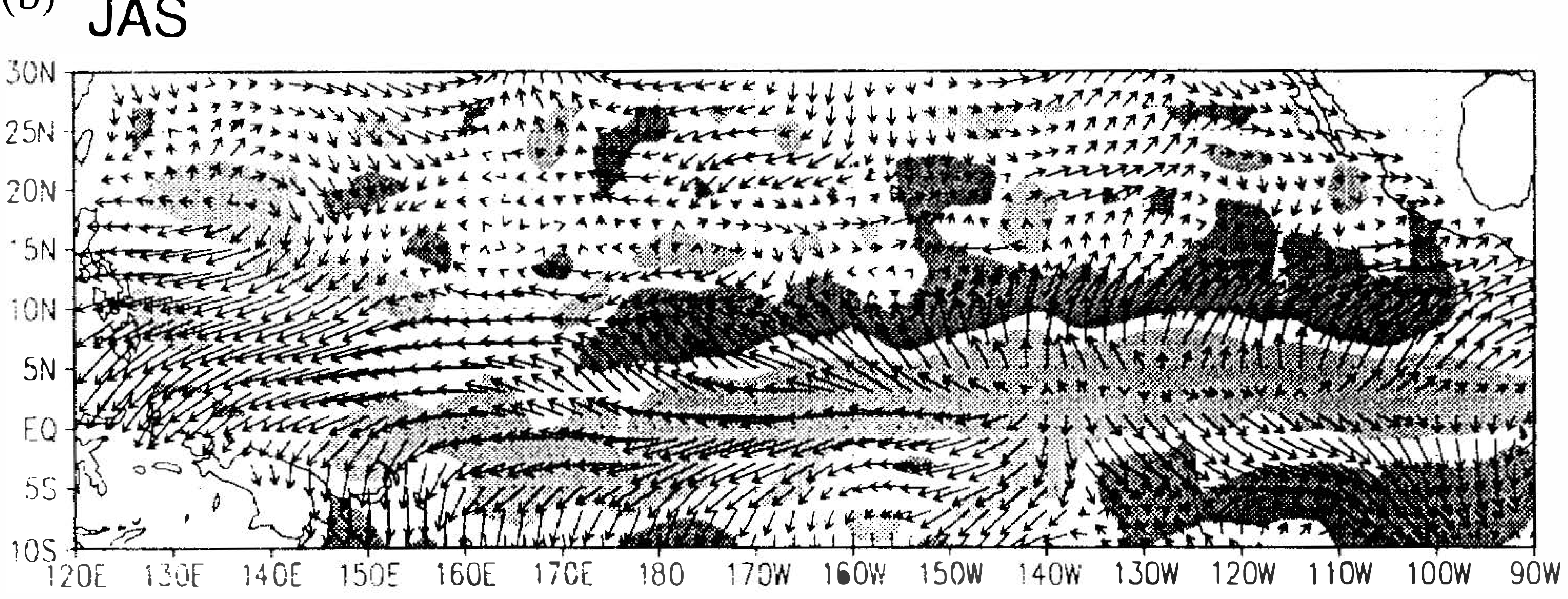

\section{(c) $\mathrm{ON}$}

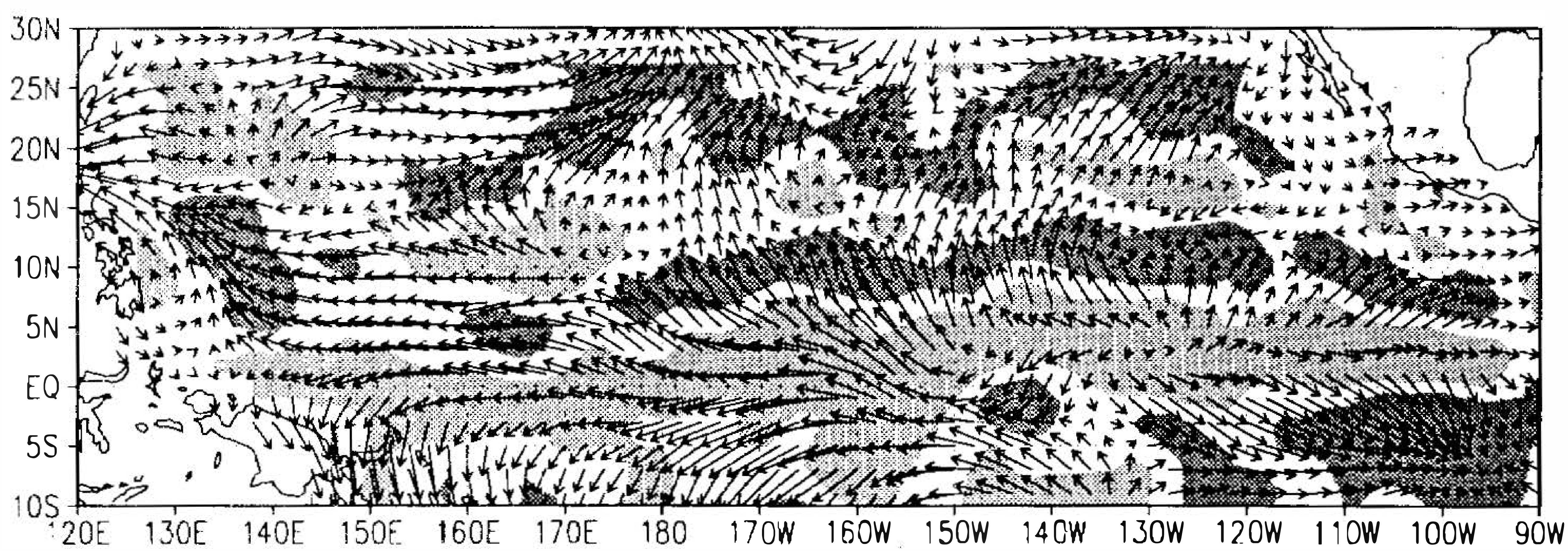

Fig. 8. Anomalous sea-level composited circulations (arrows, in $\mathrm{m} / \mathrm{s}$ ) for COLD years in (a) the early season (AMJ), (b) the main season (JAS), and (c) the late scason $(\mathrm{ON})$. Also shown are the corresponding convergence fields, where the. areas with values greater than are shaded (dark-convergence; light-divergence). 
would greatly suppress the generation of tropical storms over the WNP. Except for 1964, the other three years considered here are confirmed to be with a low $\langle\mathrm{TY}\rangle_{\mathrm{wnp}}$. Furthermore, according to Table 1 , the lower $\langle\mathrm{TY}\rangle_{\mathrm{wnp}}$ generally corresponds to a reduced $\langle\mathrm{TY}\rangle_{\mathrm{tw}_{\mathrm{w}}}$. It is thus understandable why the statistics indicate that $\langle\mathrm{TY}\rangle_{\text {tw }}$ tends to be low during the cold years. The anti-cyclonic flow (and the corresponding divergence field) remains there in the late season, but with a smaller convergence region to its south. Those circulation features (in both the main and the late seasons) are significant as confirmed from a Student $\mathrm{t}$-test (95\% confidence level; not shown). In the early season, a weak anti-cyclonic circulation can be found to the east of the Philippines, and a large cyclonic flow is found mainly north of $15^{\circ} \mathrm{N}$, extending from $120^{\circ} \mathrm{E}$ to $160^{\circ} \mathrm{E}$. However, the t-test (not shown) shows only a few points over the WNP (mainly to the east of $160^{\circ} \mathrm{E}$, or to the south of $5^{\circ} \mathrm{N}$ ) that are significant (95\%), indicating the circulation in the early season is either quite different from case to case, or close to normal in each case.

The composite of COOL years is shown in Figure 9. Significant cyclonic circulation together with a large-scale convergence field over the WNP can be found in the early season. It is located over $\left(20^{\circ} \mathrm{N}, 140^{\circ} \mathrm{E}\right.$ ), which spreads from at least $124^{\circ} \mathrm{E}$ (the western boundary of the data domain) to the international dateline, and from $5^{\circ} \mathrm{N}$ to beyond $30^{\circ} \mathrm{N}$. This is almost opposite to the findings revealed in the main season of COLD years, though it covers a broader area, albeit of weaker intensity. Such a large-scale dynamical condition is undoubtedly preferential to the generation of tropical storms over the WNP in the early season. Although that does not necessarily result in the earlier occurrence of ITYs in Taiwan, it at least increases the possibility from a statistical point of view. By comparing this with the data from the JMA (1993), it is noted that ten out of eighteen years since 1960, when there were four (or more) typhoons over the WNP in AMJ (averaged 3.51), did correspond to at least one ITY in Taiwan in the early season. Furthermore, the data here indicate that there tends to be more $\langle\mathrm{TY}\rangle_{\mathrm{tw}}$ if the typhoon season come earlier ( 9 out of 14 cases) in Taiwan. Therefore, this feature at least provides a preferential large-scale dynamical background that is consistent with more $\langle\mathrm{TY}\rangle_{\mathrm{tw}}$ in those COOL years. The large-scale pattem seems to propagate eastward in the main season, as suggested from the middle panel of Figure 9. In the meantime, a hint of an anti-cyclonic circulation seems to appear over the Philippine area. The circulation in the late season is dominated by an anti-cyclonic flow to the west of $140^{\circ} \mathrm{E}$, while the cyclonic feature is primarily located to the east of $140^{\circ} \mathrm{E}$ with weakened intensity.

It is interesting to note that there is a cyclonic circulation located to the east of $140^{\circ} \mathrm{E}$ through the WARM years (Figure 10). This is not surprising since the strong anomalous equatorial westerlies in the central Pacific are expected toward the boreal ENSO winters (e.g., Rasmusson and Carpenter 1982; Rasmusson and Wallace 1983). There is also a strong convergent zone over the climatological location of tropical storm genesis as shown in the main season. It appears that such a large-scale dynamical condition is not unfavorable to the generation of tropical cyclones, though the location of origin may be shifted eastward accordingly. Indeed, the annual total number of typhoons over the WNP in the WARM years are not necessary in the lower end (e.g., in 1972, see Table 1). Then, the question is to ask why the circulation is associated with an reduction in $\langle\mathrm{TY}\rangle_{\mathrm{t} w}$. Figure 11 shows the largescale background circulation (on $700 \mathrm{hPa}$ ) for recurving-south tropical storms over the WNP compiled by Harr and Elsberry (1991, their Figure4). One should note that the pattern within the domain that is of interest is similar to the corresponding patterns presented in Figure 10, especially panels (a) and (b). (Here, it is assumed that the surface anomalous features can be approximated by the $700 \mathrm{hPa}$ anomaly flows.) It is apparent that the dominant anti-cyclonic 
(a)

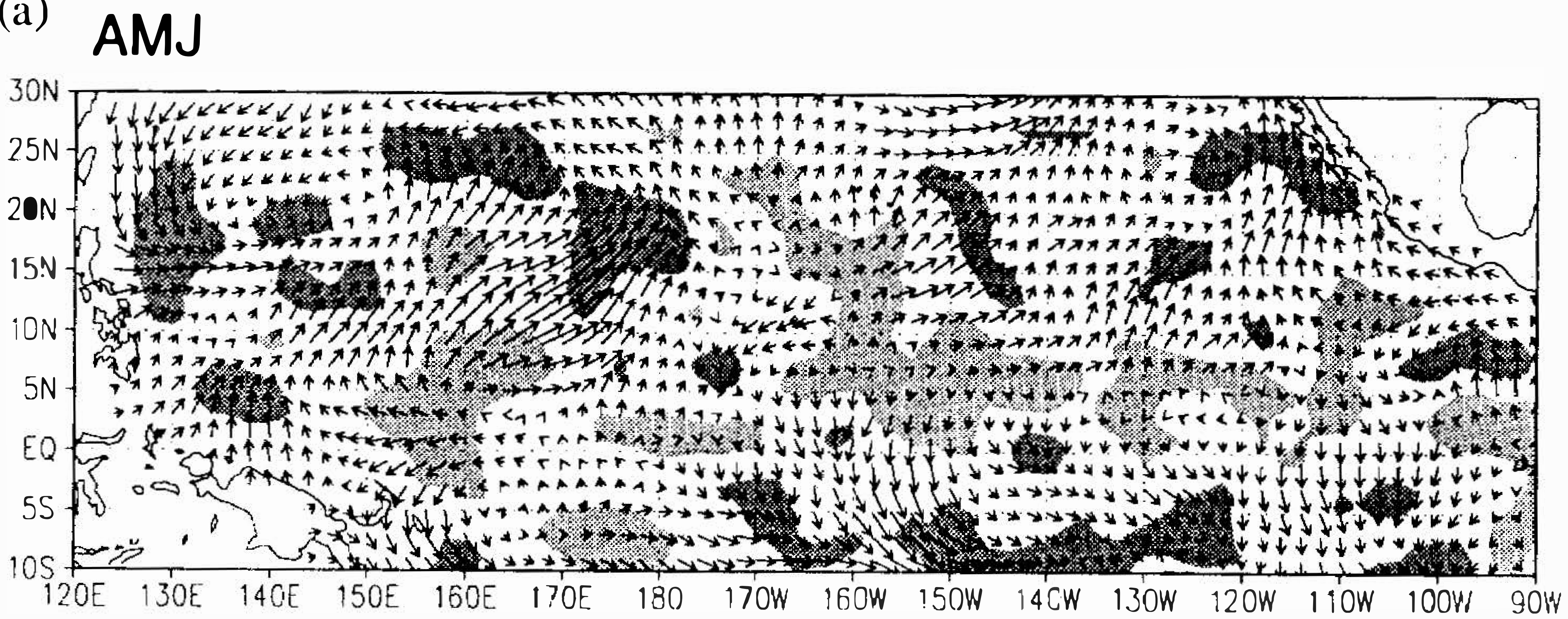

(b)

JAS

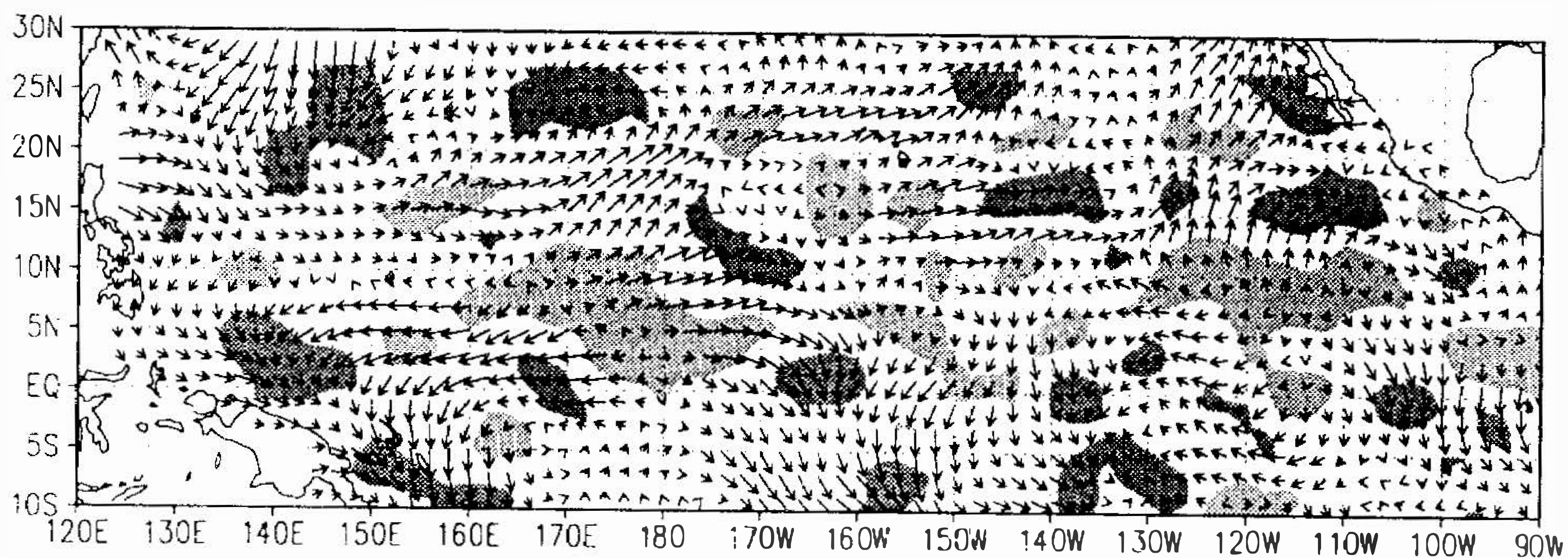

(c) $\mathrm{ON}$

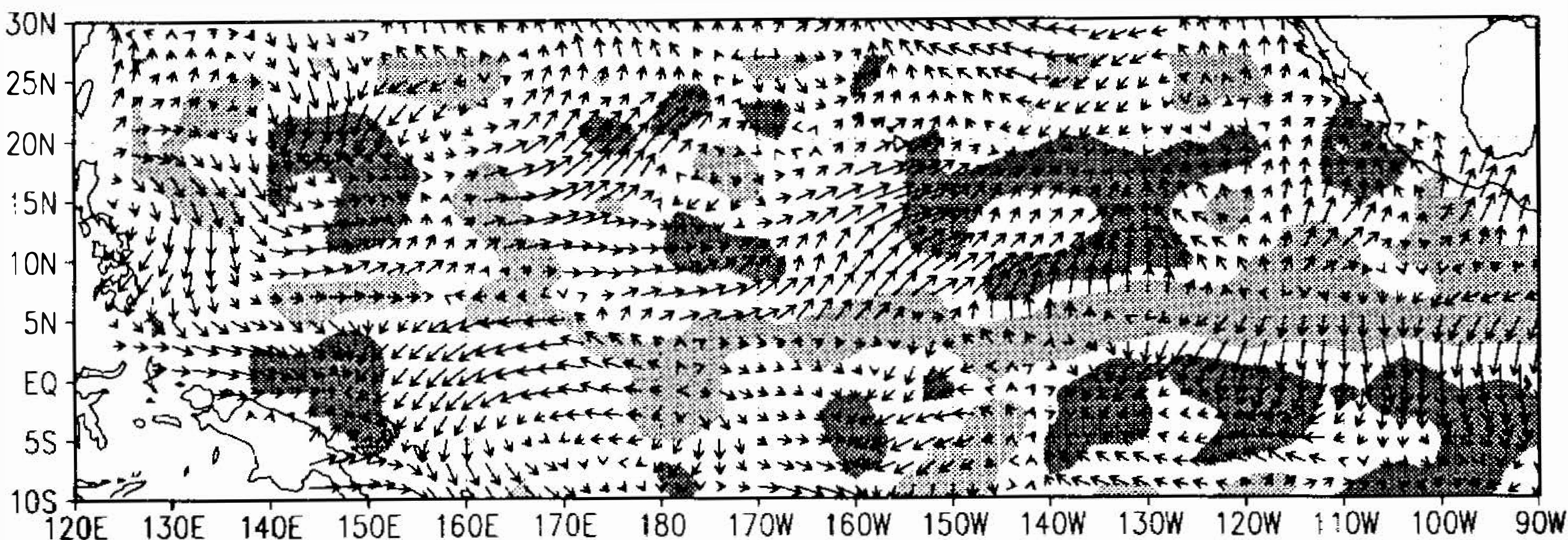

Fig. 9. Anomalous sea-level composited circulations (arrows, in $\mathrm{m} / \mathrm{s}$ ) for COOL y'ears in (a) the early season (AMJ), (b) the main season (JAS), and (c) the late season $(\mathrm{ON})$. Also shown are the corresponding convergence fields, where the areas with values greater than are shaded (dark-convergence; light-divergence). 
(a) $\mathrm{AMJ}$

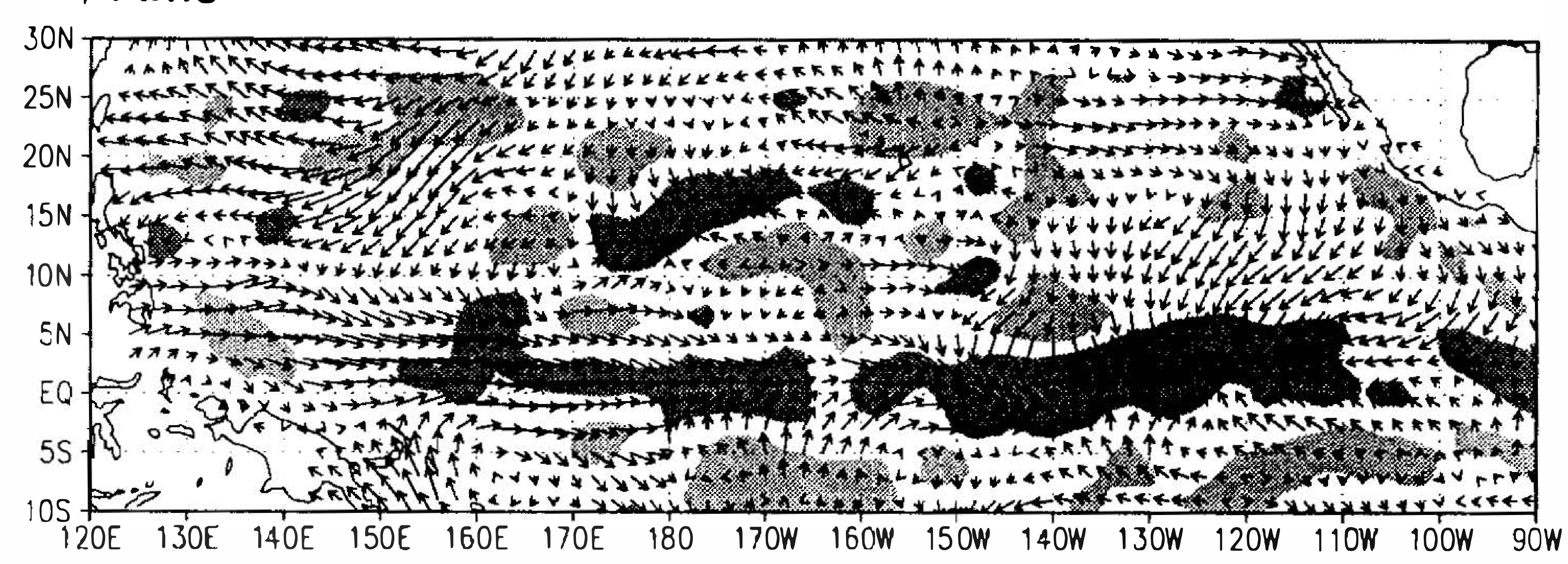

(b) JAS

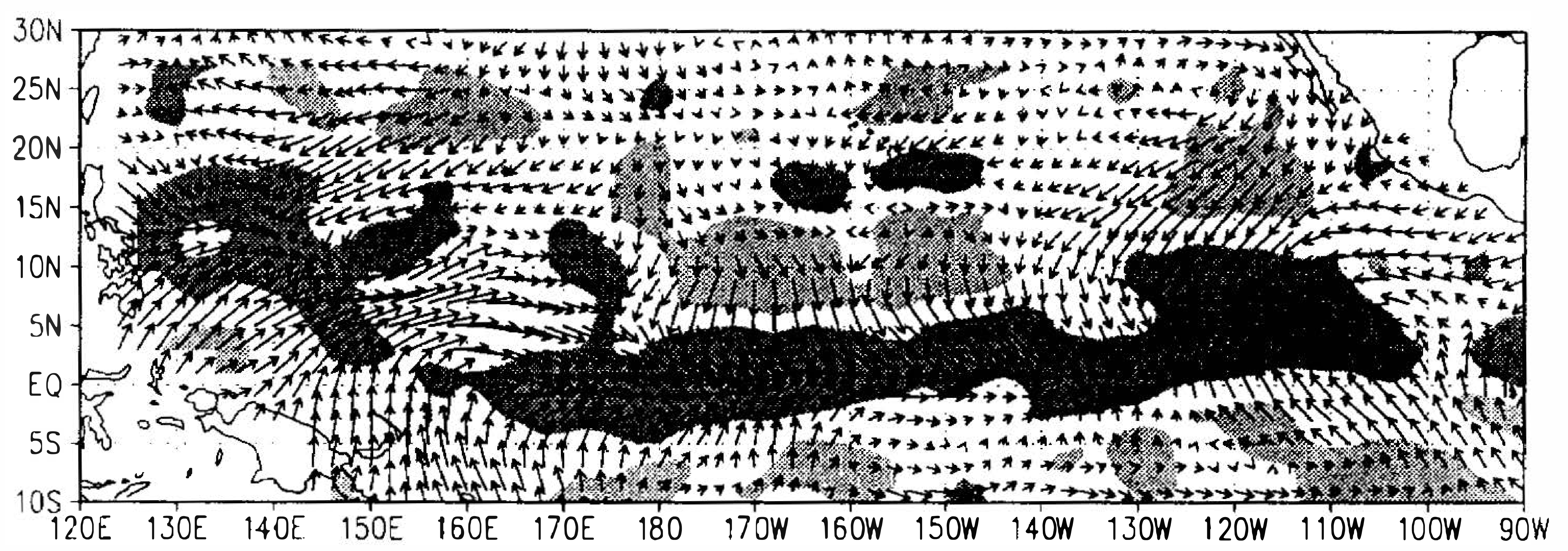

(c) $\mathrm{ON}$

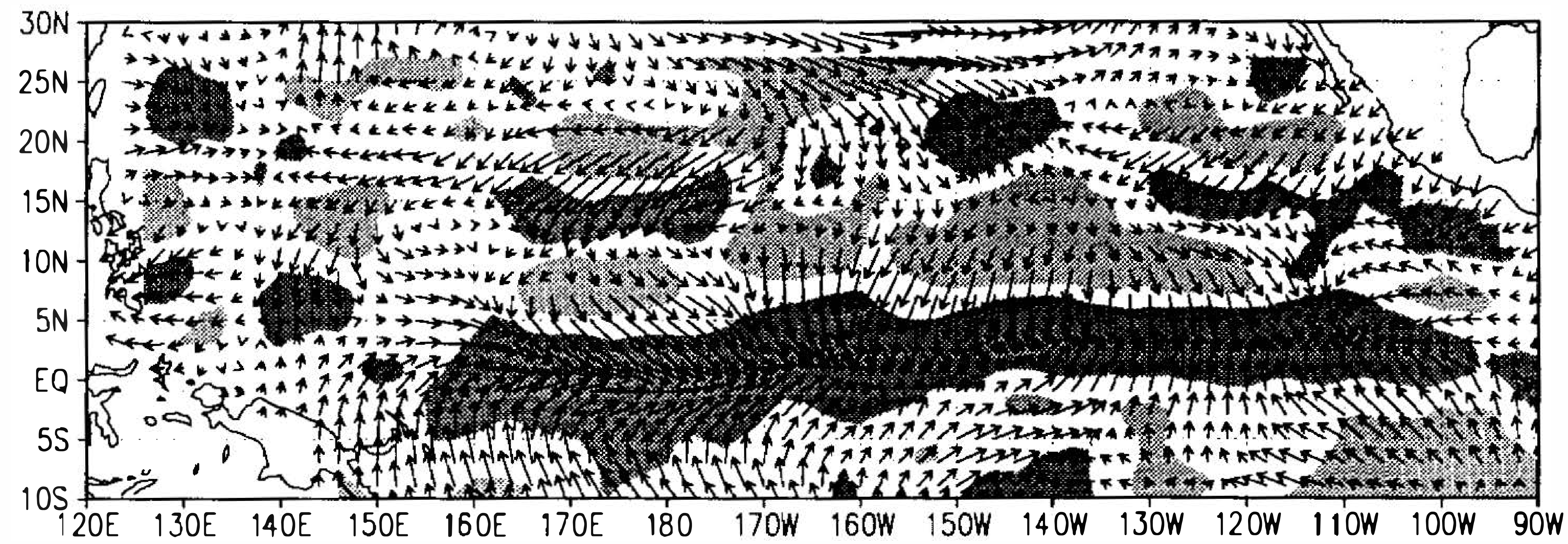

Fig. 10. Anomalous sea-level composited circulations (arrows, in $\mathrm{m} / \mathrm{s}$ ) for WARM years in (a) the early season (AMJ), (b) the main season (JAS), and (c) the late season $(\mathrm{ON})$. Also shown are the corresponding convergence fields, where the areas with values greater than are shaded (dark-convergence; light-divergence). 
flows centered near along $150^{\circ} \mathrm{E}$ generally steer the tropical storms to recurve northward. As such, the occurrence of ITYs in Taiwan is reduced. In other words, Taiwan is probably not in the preferential storm track with such a large-scale circulation feature.

It is now clear that different responses of atmospheric circulation to different underlying surface conditions, in turn, at least partially control the annual frequency of ITYs in Taiwan. Generally speaking, the large-scale circulation in the cool years is such that it is favorable to the storm formation over the WNP, especially in the early season. This suggests that the annual number of ITYs in Taiwan are likely to be higher than normal in the cool years, which is consistent with the observation. On the other hand, the unfavorable large-scale dynamical condition in the cold years suppresses the activities of tropical cyclones over the WNP in both the main and late seasons. As such, the chance for Taiwan and the nearby regions to be affected by typhoons is greatly reduced. In the warm years, the typhoon activities over the WNP are not necessarily weakened by the large-scale flows, except for a perhaps eastward displacement. However, the preferential storm track is generally not directed to Taiwan or nearby areas, which results in a mostly mediate or less than normal number of ITYs in Taiwan.

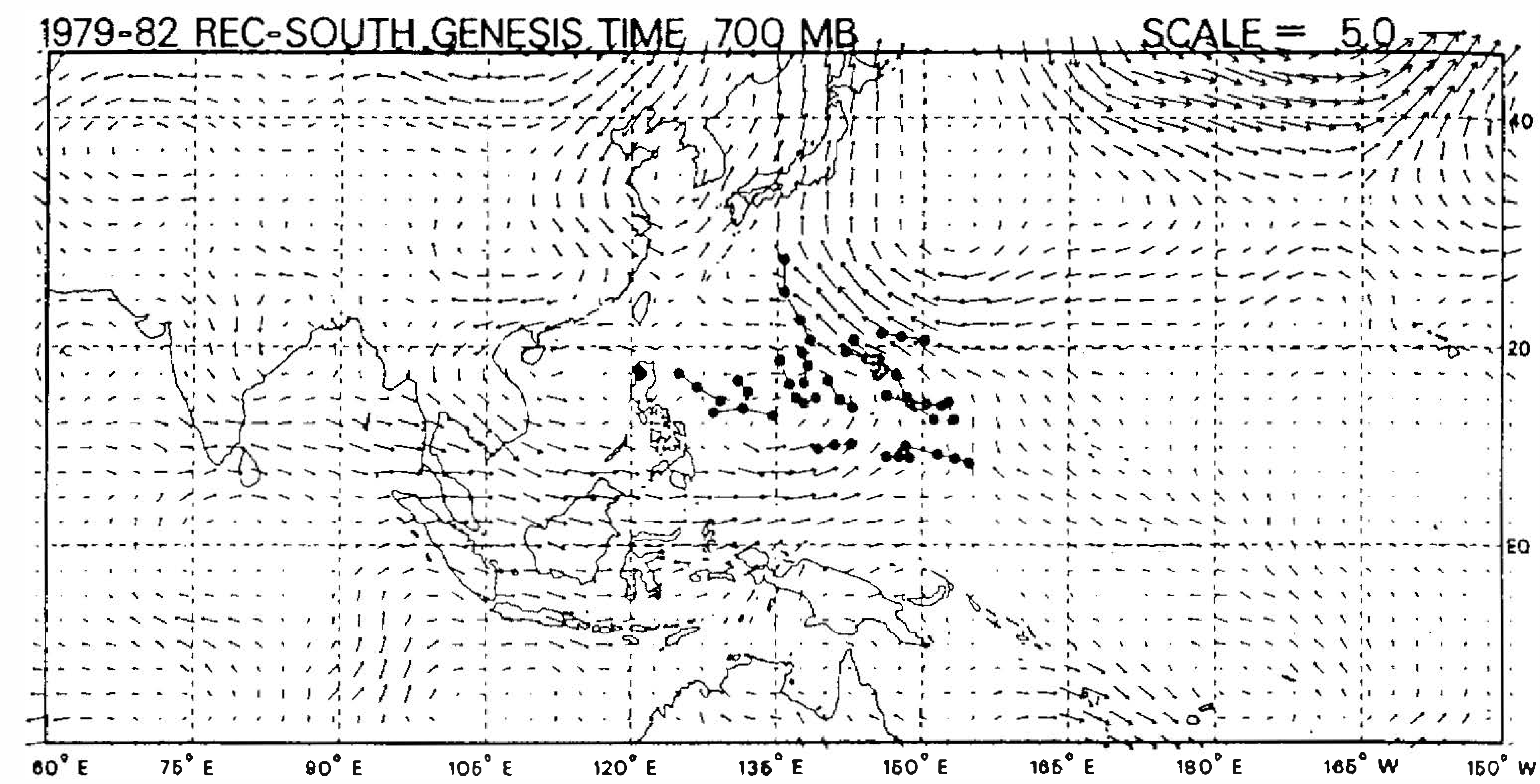

Fig. 11. Anomalous $700 \mathrm{hPa}$ winds $(\mathrm{m} / \mathrm{s})$ composited from the initial $24 \mathrm{~h}$ of recurving-south tropical cyclones. The positions of the tropical cyclones are represented by dots. Fifty-two individual maps are included in this composite. (Reproduced from Harr and Elsberry 1991, their Figure 4.)

\section{CONCLUDING REMARKS}

In this study, the possible relationship between the interannual variability of ITY activities in Taiwan and the SSTAs over the equatorial eastern Pacific has been explored. It was found that the annual frequency of ITYs in Taiwan is likely related to the ENSO (SSTA) index. Their association is not a simple linear correlation, but rather a nonlinear one. The nonlinear relationship is such that the annual number of ITYs in Taiwan is about average to less-than-normal when the SSTA index is warmer, while the number increases when SSTA 
is cooler. However, when the SSTA becomes too cold $\left(\leq-1.0^{\circ} \mathrm{C}\right)$, the annual total actually gets smaller than normal instead of getting larger. This observation appears to be beneficial in improving the long-term forecast on ty'phoon activities in the Taiwan area, provided that the SSTAs over the equatorial eastern Pacific can be accurately predicted.

The composite analysis suggested that such an intriguing relationship can be mainly attributed to different atmospheric responses over the WNP region to changes in underlying SSTAs over the equatorial eastern Pacific. In the cold years, there is an associated lowertropospheric large-scale anti-cyclonic circulation accompanied by a large divergence field over the climatological formation zone of tropical cyclones over the WNP. Such an unfavorable large-scale feature would suppress the generation of tropical storms in the main and late typhoon seasons, thereby reducing the probability of visiting typhoons in the Taiwan area. In contrast, there is large-scale cyclonic circulation with convergence located over the WNP in the cool years, especially in the early typhoon season, which is more favorable to the formation of tropical cyclones. Consequently, the annual total number of ITYs in Taiwan is likely to increase. As for the warm years, the induced cyclonic circulation over the eastern part of the WNP (east of $140^{\circ} \mathrm{E}$ ) is actually favorable to storm-genesis over the same region. However, the associated anti-cyclonic circulation to the north is in such a position that it may drive most of the storms to recurve northward before approaching Taiwan or nearby areas. In other words, Taiwan tends to be out of the preferential storm track under such a large-scale configuration. As a result, the annual number of ITYs is generally no more than the average. It is interesting to note that the activities of typhoon invasion in a warm year are not necessarily as inactive as in a cold year because the typhoon activities over the WNP in the former period have mostly not been suppressed as in the latter, but only been displaced eastward. Such a displacement of the preferred storm-genesis region may also contribute to the reduction in the number of annual ITYs for the storms being generally farther from Taiwan than otherwise.

Since this is an exploratory work, the search for a possible statistical relationship between the characteristics of invaded typhoons in Tai wan and the ENSO indices is by no mean comprehensive. Other ENSO parameters, such as the Niño 4 index or SSTA changes, should also be investigated. As a matter of fact, a preliminary analysis suggests that yearly SSTA trends could be a better indicator of the annual typhoon activities in Taiwan (Chang, 1996). It should be noted that the proposed interpretation of the statistical results with mean large-scale circulations is far from complete since other factors are also important in determining the track of typhoons. Since only surface anomalous circulations on a restricted domain have been investigated, a further investigation of 3-dimensional flows on a larger domain is desired to avoid any bias arising from this study. The finding may also shed some light on the annual activity of tropical storms over the WNP and its relationship with the ENSO cycle.

Acknowledgments This work was done at Lamont-Doherty Earth Observatory (LDEO) of Columbia University when the author was on leave from the CWB, Taiw'an. The author wishes to thank Drs. Y. Kushnir, G. Berri, and B. Zhang for helpful discussions throughout the course. Thanks are also due to Mr. M. Ishii for kindly providing the data of the ENSO indices. The FSU pseudo-stress data are accessed from LDEOs computing facilities. Ms. H.-C. Ho's proof reading of the manuscript is also highly appreciated. Comments from two anonymous reviewers help to greatly improve the presentation of the original manuscript. The author is partly supported by the NOAA through the International Research Institute for Climate Prediction/Pilot Project. 


\section{REFERENCES}

Chan, J. C. L., 1985: Tropical cyclone activity in the Northwest Pacific in relation to the El Niño/Southern Oscillation phenomenon. Mon. Wea. Rev., 113, 599-606.

Chan, J. C. L., 1990: The influence of sea-surface temperatures on tropical cyclones in the western North Pacific. Abstracts of the Int. TOGA Scientific Conf. Honolulu, HI.

Chang, J.-C. J., 1996: El Niño and Invaded Typhoons in Taiwan. Proc. 1995 CWB Conference on Weather Analysis and Forecasting, and Marine Meteorology, 503-509 (in Chinese).

Chi, K. H., 1978: The typhoon during past eighty years in Taiwan. CWB Tech. Rept., Taipei, Taiwan, 106pp.

Dong, K., 1988: El Niño and tropical cyclone frequency in the Australian region and the northwest Pacific. Aust. Meteor. Mag., 36, 219-255.

Downie, N. M., and R. W. Heath, 1965: Basic Statistical Methods, 2nd ed. Harper and Row, New York, NY, 196-210.

Emanuel, K. A., 1986: An air-sea interaction theory for tropical cyclones. Part I: Steady-state maintenance. J. Atmos. Sci., 43, 585-604.

Goldenberg, S. B., and J. J. O'Brien, 1981: Time and space variability of tropical Pacific wind stress. Mon. Wea. Rev., 109, 1190-1207.

Halpert, M. S., and C. F. Ropelewski, 1992: Surface temperature patterns associated with the Southern Oscillation. J. Climat., 5, 577-593.

Harr, P. A., and R. L. Elsberry, 1991: Tropical cyclone track characteristics as a function of large-scale circulation anomalies. Mon. Wea. Rev., 119, 1448-1468.

Hsiao, C. K., C. K. Wang, and Y. Lin, 1988: The study of the objective definition of invaded typhoons in the Taiwan area. A CWB research project 1989, No. 263, Taipei, Taiwan, 23pp.

Hsiao, C. K., 1993: The climatic change during the past centenary in the Taiwan area. Proc. 3rd Symposium on the Impact of Climatic Change on Agricultural Production in the Pacific Rim, CWB, Taipei, Taiwan, 177-200.

Hsu, H.-H., and G.-H. Chen, 1994: Relationship between the atmospheric low-frequency variability in the Taiwan area and tropical oceans and atmosphere. The CWB Collected Papers No. 014, Taipei, Taiwan, 33-58 (in Chinese, with English abstract).

Hsu, M.-T., 1949: Complete meteorological data in the Taiwan area. Part IV: Typhoons (I), the CWB, Taipei, Taiwan, 213pp. (in Chinese).

JMA, 1991: Atmospheric and oceanic conditions in the tropics and tropical cyclones in 1991. Annual Report of the RSMC Tokyo-Typhoon Center 1991, Japanese Meteorological Agency, 25-26.

JMA, 1993: Typhoon-related data. Annual Report of the RSMC Tokyo-Typhoon Center 1993, Japanese Meteorological Agency, 49-54.

Lander, M. A., 1994: An. exploratory analysis of the relationship between tropical storm formation in the western North Pacific and ENSO. Mon. Wea. Rev., 122, 636-651. 
Li, C., 1988: Actions of typhoon over the western Pacific (including the South China Sea) and El Niño. Adv. Atmos. Sci., 5, 107-115.

Ramage, C. S., and A. M. Hori, 1981: Meteorological aspects of El Niñno. Mon. Wea. Rev., 109, 1827-1835.

Rasmusson, E. M., and T. H. Carpenter, 1982: Variations in tropical sea surface temperature and surface wind fields associated with the Southern Oscillation/El Niño. Mon. Wea. Rev., 110, 354-384.

Rasmusson, E. M., and J. M. Wallace, 1983: Meteorological aspects of the El Niño/Southern Oscillation. Science, 222, 1195-1202.

Ropelewski, C. F., and M. S. Halpert, 1987: Global and regional scale precipitation patterns associated with the El Niñno/Southern Oscillation. Mon. Wea. Rev., 115, 1606-1626.

Ropelewski, C. F., and M. S. Halpert, 1989: Precipitation patterns associated with the high index phase of the Southern Oscillation. J. Climat., 2, 268-284.

Shieh, S.-L., and C.-K. Chen, 1985: A survey of meteorological disasters over the Taiwan area. A CWB Tech. Rept., Taipei, Taiwan, 64pp.

Wu, G., and N.-C. Lau, 1992: A GCM simulation of relationship between tropical-storm formation and ENSO. Mon. Wea. Rev., 120, 958-977. 